\title{
Frequencies and Characteristics of Global Oceanic Precipitation from Shipboard Present-Weather Reports
}

NASA-CR-204894

\begin{abstract}
Ship reports of present weather obtained from the Comprehensive Ocean-Atmosphere Data Set are analyzed for the period 1958-91 in order to elucidate regional and seasonal variations in the climatological frequency, phase, intensity, and character of oceanic precipitation. Specific findings of note include the following:
\end{abstract}

1) The frequency of thunderstorm reports, relative to all precipitation reports, is a strong function of location, with thunderstorm activity being favored within $1000-3000 \mathrm{~km}$ of major tropical and subtropical landmasses, while being quite rare at other locations, even within the intertropical convergence zone.

2) The latitudinal frequency of precipitation over the southern oceans increases steadily toward the Antarctic continent and shows relatively little seasonal variation. The frequency of convective activity, however, shows considerable seasonal variability, with sharp winter maxima occurring near $38^{\circ}$ latitude in both hemispheres.

3) Drizzle is the preferred form of precipitation in a number of regions, most of which coincide with known regions of persistent marine stratus and stratocumulus in the subtropical highs. Less well documented is the high relative frequency of drizzle in the vicinity of the equatorial sea surface temperature front in the eastern Pacific.

4) Regional differences in the temporal scale of precipitation events (e.g., transient showers versus steady precipitation) are clearly depicted by way of the ratio of the frequency of precipitation at the observation time to the frequency of all precipitation reports, including precipitation during the previous hour.

The results of this study suggest that many current satellite rainfall estimation techniques may substantially underestimate the fractional coverage or frequency of precipitation poleward of $50^{\circ}$ latitude and in the subtropical dry zones. They also draw attention to the need to carefully account for regional differences in the physical and spatial properties of rainfall when developing calibration relationships for satellite algorithms.

Corresponding author address: Grant W. Petty, Dept. of Earth and Atmospheric Sciences, 1397 CIVL, Purdue University, West Lafayette, IN 47907-1397.

In final form 6 February 1995.

(C)1995 American Meteorological Society

\section{Introduction}

The need for an accurate global precipitation climatology over the ocean has been recognized for many decades, owing to the key role played by oceanic precipitation in the general circulation of the atmosphere and in the global hydrological and geochemical cycles. Because it is the average precipitation rate (or average monthly precipitation accumulation) that is of greatest direct importance for studies of atmospheric energetics and moisture budgets, most research to date has focused on the estimation of this variable by various means. Until recently, the only data available for this purpose were qualitative shipboard observations of present weather, sometimes combined with rainfall measurements from nearby coastal and island sites.

A review of early efforts to develop a precipitation climatology over the ocean is given by Tucker (1961). These efforts generally involved highly indirect estimates based on extrapolation from nearby continents and on observations of sea surface salinity. Tucker proposed to estimate rainfall more directly from coded shipboard present-weather observations. He assigned calibrated weights (based on land-station observations in the United Kingdom) to various categories of codes representing precipitation and analyzed $5 \mathrm{yr}$ of ocean weather ship observations to derive patterns of precipitation amount over the North Atlantic.

Later authors (Reed 1979; Reed and Elliott 1979; Dorman and Bourke 1979, 1981) refined and extended Tucker's method, emphasizing the correction of systematic regional differences in the average precipitation intensity associated with various reported present weather codes. Jaeger (1983) used a different approach, basing his estimates of monthly precipitation accumulation over the ocean in part on precipitation frequency estimates extracted from the U.S. Navy Marine Climatic Atlas of the World (U.S. Navy 1974 , $1976,1977,1978,1979)$. These in turn were based on shipboard present-weather reports compiled for the period 1854-1978. Legates and Willmott (1990) have 
contributed the most recent oceanic precipitation climatology, based partly on a synthesis of techniques and data from Dorman and Bourke $(1979,1981)$ and Jaeger (1983).

Regardless of the method used, all of the above authors recognized that the estimation of quantitative precipitation amounts from the qualitative weather reports transmitted by ships of opportunity is a task fraught with uncertainties. Even for well-trained observers, the visual classification of precipitation intensity and character by shipboard weather observers is an inherently subjective task, notwithstanding comprehensive reporting rules published by the World Meteorological Organization (WMO) (e.g., World Meteorological Organization 1974) and other agencies overseeing the collection of synoptic reports. As pointed out in the U.S. Navy Marine Climatic Atlas, precipitation is "one of [the elements] most subject to error in interpretation. This derives from a number of causes such as coding practices, observers' preference for certain present-weather codes and other biases."

Furthermore, even if quantitative criteria could be rigorously adhered to in the reporting of rain intensity, the three conventional classifications "slight," "moderate," and "heavy"- bounded by nominal thresholds of 2.5 and $7.5 \mathrm{~mm} \mathrm{~h}^{-1}\left(0.1\right.$ and $\left.0.3 \mathrm{in.} \mathrm{h}^{-1}\right)$ (FMH 1978)are inadequate to characterize the wide range of observed precipitation intensities. For example, instantaneous rain rates in the Tropics may regularly exceed $150 \mathrm{~mm} \mathrm{~h}^{-1}$, or about 20 times the minimum intensity for classification as "heavy." Moreover, most of the operational present-weather codes transmitted in shipboard synoptic weather reports do not even distinguish between moderate and heavy precipitation; thus, intensity is classified only as "slight" or as "moderate or heavy." Clearly, the derivation of climatological rain rates from routine ship reports alone is impossible without recourse to rather sweeping assumptions (either explicit or implicit) concerning the underlying rain-rate-probability distribution function and its homogeneity in time and space.

Finally, the sampling density afforded by ships of opportunity is extremely poor, especially over the majority of the southern oceans. While the sampling may be adequate to derive climatological averages of certain precipitation properties (the focus of this paper), it is often inadequate for studying shorter-term variability in precipitation patterns over all but the most densely sampled areas.

Because of these and other problems with conventional reports over the ocean, there is now tremendous interest in extracting quantitative estimates of precipitation from satellite observations of the atmosphere. Already, operational visible, infrared, and microwave sensors are being used to derive experimental estimates of monthly precipitation over the global oceans, and considerable effort is being devoted to the validation and improvement of the respective algorithms (e.g., Arkin aud Xie 1994; Barrett et al. 1994a). A Tropical Rainfall Measuring Mission (Simpson et al. 1988), scheduled for launch in 1997, will be the first satellite mission dedicated primarily to the task of developing a rainfall climatology, in this case within the latitude belt between $30^{\circ} \mathrm{N}$ and $30^{\circ} \mathrm{S}$.

While the quest for satellite-derived rainfall climatologies is propelled by the reasonable belief that satellites should eventually be able to provide information superior to that obtainable from sparse and mostly qualitative surface observations alone, the fact remains that competing satellite algorithms applied to the same sensor data continue to yield rather large (factor of 2 or more) differences in precipitation estimates; furthermore, the differences are regionally and latitudinally dependent (Barrett et al. 1994b). This observation suggests, among other things, that further calibration and validation of algorithms over a variety of regions, as well as improvements to the underlying retrieval strategies, may be necessary before satellite estimates of oceanic precipitation totals can be regarded as reliable everywhere. Unfortunately, the same lack of calibrated ocean surface rainfall data that motivates the development of satellite techniques also hampers their global calibration and validation.

The lack of surface rainfall measurements for calibrating satellite-derived rainfall totals is well known and will undoubtedly remain a serious problem for some time to come; it is perhaps less widely recognized that current published satellite retrieval algorithms continue to differ markedly even in the retrieved frequency (or, equivalently, average fractional coverage) of precipitation over various regions. Given that passive microwave techniques in particular are often billed as "physically direct," the ability of these techniques to correctly classify a pixel as raining or not raining might be regarded as an even more fundamental measure of performance than the area-averaged magnitude of the retrieved rainfall.

Also, an unavoidable source of uncertainty in current-generation satellite estimates of global precipitation is that the techniques used are inherently sensitive to the macro- and microphysical characteristics of the precipitating cloud system-for example, whether it is spatially extensive or localized, whether it is convective or stratiform, and whether it is warm-cloud precipitation dominated by collision/coalescence of liquid water droplets or cold-cloud precipitation dominated by mixed-phase microphysics (Wilheit 1986). However, because relatively little is known about the 
spatial and seasonal variability of these characteristics over the global oceans, the actual potential for regionally or seasonally dependent biases in precipitation estimates has never been adequately assessed.

Third, while liquid-equivalent precipitation rate is undoubtedly the variable of greatest interest for many purposes, other characteristics of precipitation over the ocean, such as frequency, phase, and physical character (e.g., convective versus stratiform), may be of considerable climatological interest in their own right, not least because of what they tell us about regional differences in the physical and dynamic processes of the atmosphere.

Motivated by all three of the considerations cited above, an analysis of the statistics of various presentweather codes reported by ships of opportunity has been undertaken for the 34-yr period covering 1958-91. The result of this analysis may be the most detailed global climatology to date of the frequency of occurrence and, especially, the general physical properties of global oceanic precipitation.

The surface precipitation frequencies derived herein should thus provide the first solid basis for evaluating the ability of satellite techniques to correctly estimate average fractional coverage by precipitation over remote ocean areas. Furthermore, the precipitation characteristics presented below should provide new insight into the regional and seasonal variability of precipitation properties to which satellite techniques are sensitive. Finally, it is felt that some characteristics of global precipitation elucidated in this analysis are indeed noteworthy from a purely climatological point of view.

\section{Comprehensive Ocean-Atmosphere Data Set}

The recent availability of the Comprehensive Ocean-Atmosphere Data Set (COADS) (Woodruff et al. 1987) in digital form has made it convenient to analyze a long time series of global ship reports for the purpose of extracting climatological statistics. In this study, we employ the Compressed Marine Reports (CMR.5) format COADS product. The CMR record format provides for the archival of much of the same information as is contained in the standard ship synoptic code, including air and sea surface temperature, dewpoint, wind speed and direction, cloud coverage and type, and present-weather codes. In addition, quality control flags are included that indicate whether certain variables fall within the normal climatological range associated with the time and location of the report. Details of the COADS record formats and archive contents may be found in the document Comprehensive Ocean-Atmosphere Data Set: Release 1 (Slutz et al. 1985).

For the purpose of this study, the present-weather (ww) code is the variable of primary interest. Other variables are employed here strictly for screening purposes.

The majority of records contained in the COADS dataset are derived from routine marine synoptic reports of observations taken at the standard times of $0000,0600,1200$, and 1800 UTC. A smaller number are taken at intermediate 3-h intervals, or at other nonstandard times. Some COADS reports are derived from unmanned sources (e.g., buoys), but these constitute a small fraction of the total and play no role in this study owing to the absence of present-weather information.

\section{a. Present-weather codes}

The synoptic present-weather element of a COADS record consists of a two-digit code ranging from 00 to 99. The selection of a single unique code to represent observed conditions at a particular time and place is accomplished via a well-defined set of criteria and priorities published by the World Meteorological Organization (1974). Of the 100 possible ww codes, 66 are associated-either explicitly or by strong implicationwith precipitation. For clarity and convenience in the following discussion, the definitions of these 66 codes are reproduced in Table 1.

If the specific conditions represented by more than one code are consistent with the observed conditions, it is generally the code with the higher numerical value that must be reported. This implies that, for example, the reporting of fog at the station (codes 40-49) would take precedence over the reporting of past precipitation (codes 20-29) or of precipitation and related phenomena observed in the vicinity of, but not necessarily at, the station at the time of observation (codes 13-19). Also, the reporting of current precipitation in any form (codes 50 and greater) takes precedence of the reporting of past or nearby thunderstorm or lightning activity. The potential for minor statistical biases arising from these rules of precedence should be kept in mind throughout the remainder of this paper.

Many of the ww code definitions differ in rather subtle respects from one another. For the sake of determining the gross climatological characteristics of overocean precipitation, the 66 codes were therefore grouped according to precipitation intensity, phase, and character. Within each of these three categories, each code was assigned to one of four possible classes, the definitions of which appear in Table 2.

The results of this classification are summarized in Table 3. Note that while a total of 64 combinations of 
TABLE 1. Definitions of present-weather (ww) codes pertaining to precipitation.

Intensity,

phase,

ww character

Description

Codes 00 to 49 indicate no precipitation at the station (e.g., ship) at time of observation.

\begin{tabular}{|c|c|c|}
\hline 13 & $\mathbf{0 0 3}$ & lightning visible, no thunder heand \\
\hline 14 & 200 & precipitation within sight, not reaching the surface of the sea \\
\hline 15 & 000 & precipitation within sight, reaching the surface of the sea, but more than $5 \mathrm{~km}$ from the station \\
\hline 16 & 000 & precipitation within sight, reaching the surface of the sea, near to but not at the station \\
\hline 17 & 003 & thunderstorm, but no precipitation at time of observation \\
\hline 18 & 003 & squalls at or within sight of the station during the preceding hour or at time of observation \\
\hline 19 & $\infty 03$ & funnel cloud or waterspout at or within sight of the station during the preceding hour or at time of \\
\hline
\end{tabular}

Codes 20 to 29 refer to phenomena that occurred at the station during the preceding hour but not at time of observation.

$\begin{array}{lll}20 & 100 & \text { drizzle (not freezing) or snow gains } \\ 21 & 011 & \text { rain (not freezing) } \\ 22 & 021 & \text { snow } \\ 23 & 031 & \text { rain and snow or ice pellets, type (a) } \\ 24 & 031 & \text { freezing drizzle or freezing rain } \\ 25 & 012 & \text { shower of rain } \\ 26 & 022 & \text { shower of snow, or of rain and snow } \\ 27 & 003 & \text { shower of hail [ice pellets, type (b), snow pellets], or of rain and hail } \\ 29 & 003 & \text { thunderstorm (with or without precipitation) }\end{array}$

Codes 50 to 99 indicate precipitation at the station at time of observation.

$\begin{array}{lll}50 & 111 & \text { drizzle, not freezing, intermittent, slight at time of observation } \\ 51 & 111 & \text { drizzle, not freezing, continuous, slight at time of observation } \\ 52 & 111 & \text { drizzle, not freezing, intermittent, moderate at time of observation } \\ 53 & 111 & \text { drizzle, not freezing, continuous, moderate at time of observation } \\ 54 & 111 & \text { drizzle, not freezing, intermittent, heavy (dense) at time of observation } \\ 55 & 111 & \text { drizzle, not freezing, continuous, heavy (dense) at time of observation } \\ 56 & 131 & \text { drizzle, freezing, slight } \\ 57 & 131 & \text { drizzle, freezing, moderate or heavy (dense) } \\ 58 & 211 & \text { drizzle and rain, sllght } \\ 59 & 311 & \text { drizzle and rain, moderate or heavy } \\ 60 & 211 & \text { rain, not freezing, intermittent, slight at time of observation } \\ 61 & 211 & \text { rain, not freezing, continuous, slight at time of observation } \\ 62 & 311 & \text { rain, not freezing, intermittent, moderate at time of observation } \\ 63 & 311 & \text { rain, not freezing, continuous, moderate at time of observation }\end{array}$


TABLE 1. Continued

\begin{tabular}{c}
$\begin{array}{c}\text { Intensity, } \\
\text { phase, } \\
\text { character }\end{array}$ \\
ww Description \\
\hline
\end{tabular}

\begin{tabular}{|c|c|c|}
\hline 64 & 311 & rain, not freezing, intermittent, heavy at time of observation \\
\hline 65 & 311 & rain, not freezing, continuous, heavy at time of observation \\
\hline 66 & 231 & rain, freezing, slight \\
\hline 67 & 331 & rain, freezing, moderate or heavy \\
\hline 68 & 231 & rain or drizzle and snow, slight \\
\hline 69 & 331 & rain or drizzle and snow, moderate or heavy \\
\hline 70 & 221 & intermittent fall of snowflakes, slight at time of observation \\
\hline 71 & 221 & continuous fall of snowflakes, slight at time of observation \\
\hline 72 & 321 & intermittent fall of snowflakes, moderate at time of observation \\
\hline 73 & 321 & continuous fall of snowflakes, moderate at time of observation \\
\hline 74 & 321 & intermittent fall of snowflakes, heavy at time of observation \\
\hline 75 & 321 & continuous fall of snowflakes, heavy at time of observation \\
\hline 76 & 121 & ice prisms (with or without fog) \\
\hline 77 & 121 & snow grains (with or without fog) \\
\hline 78 & 121 & isolated starlike snow crystals (with or without fog) \\
\hline 79 & 030 & ice pellets, type (a) (sleet, U.S. definition) \\
\hline 80 & 212 & rain shower, slight \\
\hline 81 & 312 & rain shower, moderate or heavy \\
\hline 82 & 313 & rain shower, violent \\
\hline 83 & 232 & shower of rain and snow mixed, slight \\
\hline 84 & 332 & shower of rain and snow mixed, moderate or heavy \\
\hline 85 & 222 & snow shower, slight \\
\hline 86 & 322 & snow shower, moderate or heavy \\
\hline 87 & 202 & slight showers of snow pellets or ice pellets, type (b), with or without rain or rain and snow mixed \\
\hline 88 & 302 & moderate or heavy showers of snow pellets or ice pellets, type (b), with or without rain or rain and snow mixed \\
\hline 89 & 303 & slight showers of hail, with or without rain or rain and snow mixed, not associated with thunder \\
\hline 90 & 303 & moderate or heavy showers of hall, whth or without rain or rain and snow, mixed, not associated with thunder \\
\hline 91 & 213 & slight rain at time of observation, thunderstorm during preceding hour but not at time of observation \\
\hline 92 & 313 & moderate or heavy rain at time of observation, thunderstorm durng preceding hour but not at time of observation \\
\hline 93 & 203 & $\begin{array}{l}\text { slight snow, or rain and snow mixed, or hail, at time of observation with thunderstorm during the preceding hour } \\
\text { but not at time of observation }\end{array}$ \\
\hline 94 & 303 & $\begin{array}{l}\text { moderate or heavy snow, or rain and snow mixed, or hall, at time of observation with thunderstorm during the } \\
\text { preceding hour but not at time of observation }\end{array}$ \\
\hline 95 & 303 & thunderstorm, slight or moderate, without hail, but with rain and/or snow at time of observation \\
\hline 96 & 303 & thunderstom, slight or moderate, with hall at tme of observation \\
\hline 97 & 303 & thunderstorm, heavy, without hail but with rain and/or snow at time of observation \\
\hline 98 & 303 & thunderstorm combined with dust storm or sandstorm at time of observation \\
\hline 99 & 303 & thunderstorm, heavy, with hail at time of observation \\
\hline
\end{tabular}


TaBle 2. Precipitation intensity, phase, and character class definitions.

\begin{tabular}{cl}
\hline Code & Description \\
\hline Intensity classes \\
0 & indeterminate \\
1 & extremely light (e.g., drizzle) intensity \\
2 & light \\
3 & moderate/heavy \\
Phase classes \\
0 & indeterminate or hail \\
1 & liquid \\
2 & snow \\
3 & transition (mixed phase or freezing precipitation \\
3 & or sleet) \\
& sharacter classes \\
0 & indeterminate \\
1 & steady/intermittent \\
2 &
\end{tabular}

intensity, phase, and character codes are theoretically possible, only 31 of these are actually represented by the available ww definitions. For example, there are no "1X2" or "1X3" categories (where " $X$ " here implies a "wild card" value), because no code has been assigned to the nonexistent case of drizzle-intensity precipitation having a showery or strongly convective character.

Most codes receiving an intensity classification of " 0 " ("indeterminate") correspond to precipitation within sight of, but not at, the station at the time of observation, or else precipitation observed at the station during the hour preceding the observation time but not at the time of observation.

In a departure from the above rule, code 14 (precipitation within sight, not the surface of the sea) was assigned a nominal intensity classification of "2," since the precipitation must be intense enough to be visible to a surface observer yet light enough to evaporate before reaching the surface. This classification also has the advantage of placing $w w=14$ in a group by itself, so that it can be conveniently excluded from statistics intended to reflect the properties of surface precipitation only, as will be the case for the remainder of this paper. This distinction notwithstanding, $w w=14$ does refer to the product of precipitation processes, and its occurrence has therefore been tabulated to-
TABle 3. Precipitation intensity, phase, and character groups.

\begin{tabular}{|c|c|c|}
\hline Group & $\begin{array}{l}\text { Intensity, } \\
\text { phase, } \\
\text { character }\end{array}$ & ww \\
\hline 1 & 000 & 15,16 \\
\hline 2 & 003 & $13,17,18,19,27,29$ \\
\hline 3 & 011 & 21 \\
\hline 4 & 012 & 25 \\
\hline 5 & 021 & 22 \\
\hline 6 & 022 & 26 \\
\hline 7 & 030 & 79 \\
\hline 8 & 031 & 23,24 \\
\hline 9 & 100 & 20 \\
\hline 10 & 111 & $50,51,52,53,54,55$ \\
\hline 11 & 121 & $76,77,78$ \\
\hline 12 & 131 & 56,57 \\
\hline 13 & 200 & 14 \\
\hline 14 & 202 & 87 \\
\hline 15 & 203 & 89,93 \\
\hline 16 & 211 & $58,60,61$ \\
\hline 17 & 212 & 80 \\
\hline 18 & 213 & 91 \\
\hline 19 & 221 & 70.71 \\
\hline 20 & 222 & 85 \\
\hline 21 & 231 & 66,68 \\
\hline 22 & 232 & 83 \\
\hline 23 & 302 & 88 \\
\hline 24 & 303 & $90,94,95,96,97,98,99$ \\
\hline 25 & 311 & $59,62,63,64,65$ \\
\hline 26 & 312 & 81 \\
\hline 27 & 313 & 82,92 \\
\hline 28 & 321 & $72,73,74,75$ \\
\hline 29 & 322 & 86 \\
\hline 30 & 331 & 67,69 \\
\hline 31 & 332 & 84 \\
\hline
\end{tabular}

gether with the other forms of precipitation for possible use in future studies.

\section{b. Study sample}

A 34-yr period of COADS data was analyzed for this study, covering the years 1958 through 1991. Although the COADS archive extends as far back as 1854 , the starting year of 1958 was subjectively cho- 

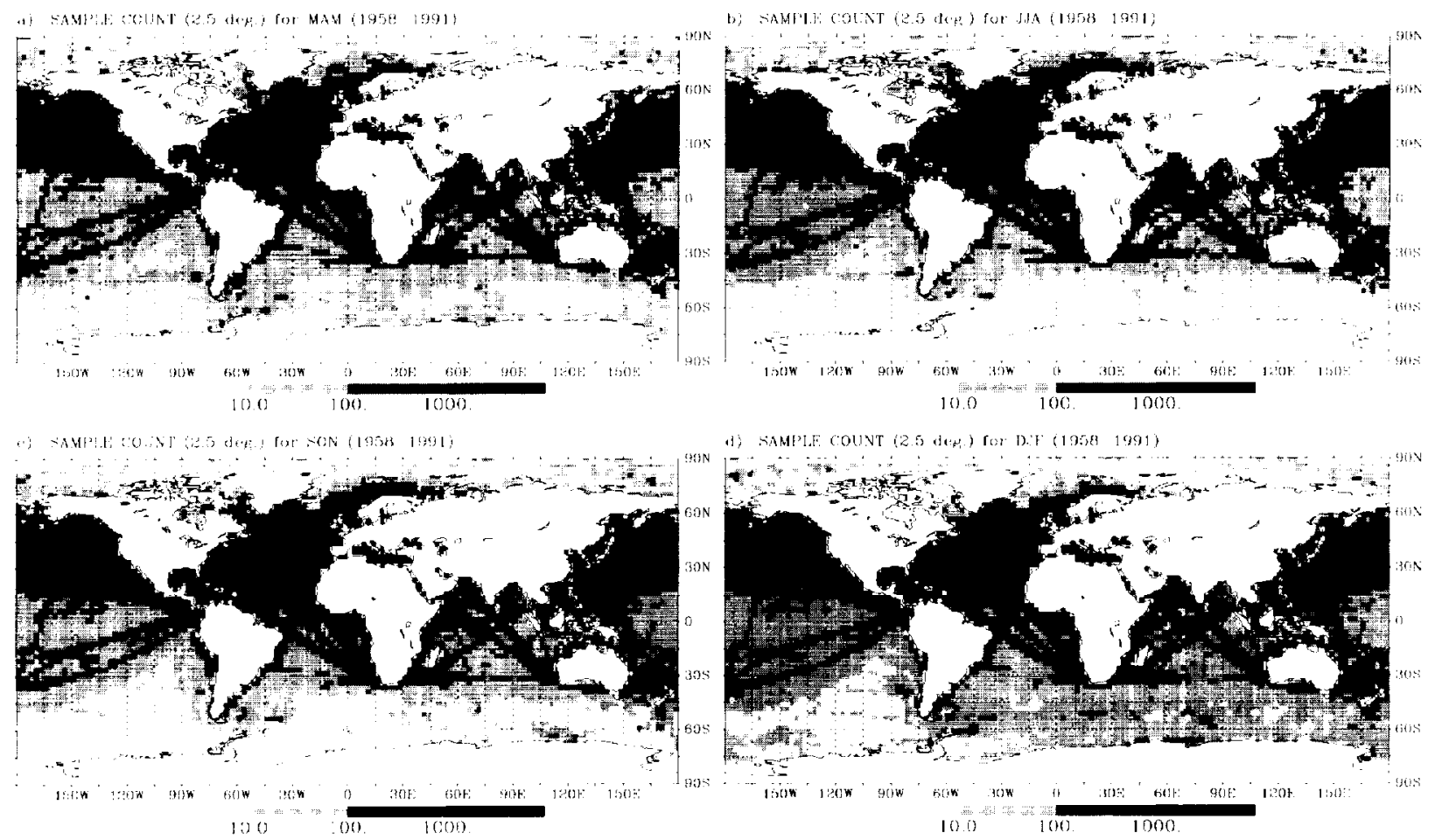

FIG. 1. Count per $2.5^{\circ}$ latitude-longitude grid box of ship reports used in the analysis.

sen so as to minimize uncertainties associated with nonstandard or variable reporting procedures during earlier periods (Reed 1979).

The total sample count of usable ship reports per $2.5^{\circ}$ latitude-longitude box is depicted graphically in Fig. 1 for each season. Major shipping lanes are clearly delineated by large sample counts. By contrast, large areas of the Southern Hemisphere, particularly the southeastern Pacific, were only rarely sampled. In particular, during the Southern Hemisphere winter, ship reports south of $45^{\circ} S$ are remarkably scarce, with a great many grid boxes having never been sampled at all during the entire 34-yr period.

A small number of reports (generally no more than $\sim 1$ per grid box) in the COADS database were found to be associated with landlocked locations (not depicted in Fig. 1). As discussed by Warren et al. (1988), these reports apparently reflect errors in the coding or transmission of the ship's location. Assuming that such erroneous reports are scattered more or less uniformly over the globe, it seems likely that a similar number of the overwater reports within in any given grid box are likely to be mislocated as well. This in turn implies that statistics may not be reliable unless the total sample size in the grid box is much greater than the random contribution from mislocated reports.

\section{c. Data limitations}

In past studies, considerable attention has been given to the so-called "fair weather bias" (Quayle 1974), attributed to the tendency of ships to avoid foul weather and/or take fewer observations during periods of foul weather. A partially counteracting "foul weather bias" may arise from the tendency of certain ships that report weather only intermittently to do so mainly when the weather is deemed significant. Another foul weather bias is hypothesized to result from ships slowing down in rough seas and thus spending more time within the stormy region. Warren et al. (1988) examined the above fair/foul weather biases primarily from the standpoint of cloud observations and found that the fair weather bias appears to prevail but is small.

With respect to the present-weather statistics derived in this study, the following additional biases are felt by the author to be of similar potential importance:

1) Systematic misclassification of precipitation type by inadequately trained observers-for example, drizzle reported as rain or vice versa; intermittent stratiform rain reported as rain showers; ice pellets reported as hail, etc. In particular, characterizations of precipitation intensity are undoubtedly made in the field at least partly by reference to what 
the crew member has commonly experienced in the past. For example, observers accustomed to heavy tropical downpours may be more likely to classify as "light" a rain intensity that would earn the classification "moderate" from an observer accustomed to conditions in the North Atlantic.

2) Day/night bias-Fewer observations are made at night, and those observations submitted may be less reliable, particularly regarding present-weather codes requiring visual identification [for example, virga (code 14) or precipitation within sight of but not at the station (codes 15 and 16)].

However, distant lightning (code 13) is probably reported more frequently at night. Partly because of the difficulty of accurately accounting for day/ night biases, this study does not attempt to examine diurnal variations in the reporting of various present-weather codes [see, however, Hahn et al. (1994), who did calculate the diurnal phase and amplitude of the frequency of local precipitation reports from ships and found a relative day-night difference on the order of $6 \%$ globally].

3) Mislocations - In data-sparse regions such as the far southern oceans, a significant fraction of the available data may consist of mislocated reports from more densely sampled regions.

In this study, no attempt is made to account for any of the above possible errors, mainly because there is still no reliable, globally applicable basis for doing so. The practice of arbitrarily including past precipitation reports (i.e., precipitation during the past hour but not at the time of observation) in previous climatologies of precipitation frequency (e.g., U.S. Navy 1974, 1976, $1977,1978,1979$ ) in order to offset the perceived underreporting of precipitation is difficult to justify, since the statistical occurrence of such reports, relative to present precipitation reports, is highly variable according to region and reflects real differences in the temporal character of the precipitation (see section $4 d$ ). There is no reason to expect that the artificial (and variable) increase in apparent precipitation frequency obtained in this way is correlated in any way with the true reporting bias.

While some effort has been made to screen out obviously faulty or unreliable reports, based in part on other reported variables, all frequencies presented below should be interpreted in light of the potential for the above-noted biases.

\section{Processing}

The initial phase of the analysis of the 34-yr COADS dataset entailed the simple tabulation of precipitation classes within each $2.5^{\circ}$ latitude-longitude grid box over the entire globe for each of the 12 calendar months, resulting in a $144 \times 72 \times 12 \times 31$ histogram of raw counts. Also computed was the corresponding $144 \times 72 \times 12$ array containing the total count of valid ww reports.

For a report to be included in the above tabulation, two criteria had to be met. First, the total cloud amount reported had to be a legitimate nonmissing value (0-8 for oktas of the celestial dome covered by cloud, or 9 for sky obscured). This limits the sample to reports made by human observers taking visual observations of sky and weather conditions and thus mitigates an important ambiguity in the interpretation of a missing value for the ww code ("//" in the original synoptic report). According to new WMO rules implemented in 1982 , a missing ww value can imply either 1) that no present-weather observation was possible (as is the case for all buoy reports) or 2) that the present weather was observed by a human observer but that it involved no reportable meteorological phenomena and that sky-cover development over time was not determined (note: after 1985, a station/weather indicator code was added to the WMO code form for ships to distinguish between the two cases; unfortunately this indicator is not available in the COADS CMR data-record format). The requirement that the total cloud cover be reported in some form largely eliminates reports of the first type from the sample, thus reducing the likelihood of a significant low bias in computed precipitation frequencies.

The second condition was that the sea surface temperature quality flag in the COADS record have a value less than or equal to zero. This criterion eliminated reports in which the reported sea surface temperature deviates by more than $2.8 \sigma$ from the smoothed median sea surface temperature for that month and region, where $\sigma$ is the smoothed upper or lower median deviation [for details, see supplement $C$ in the COADS Release 1 documentation (Slutz et al. 1985)]. The intent of this screening procedure was to reduce the number of mislocated reports in the dataset, since the reported sea surface temperature in many such cases will be inconsistent with the reported location. Undoubtedly, a few valid reports are also discarded on this basis; however, it is assumed that the potential bias introduced by discarding occasional valid reports is likely to be much smaller than that contributed by the inadvertent inclusion of grossly mislocated reports.

Once gridded histograms of precipitation groups are derived, absolute and relative frequencies of various classes of precipitation reports may be examined in detail. In general, two types of statistics are considered here: 1) the frequency of certain classes of precipitation reports relative to all valid $w w$ reports, 


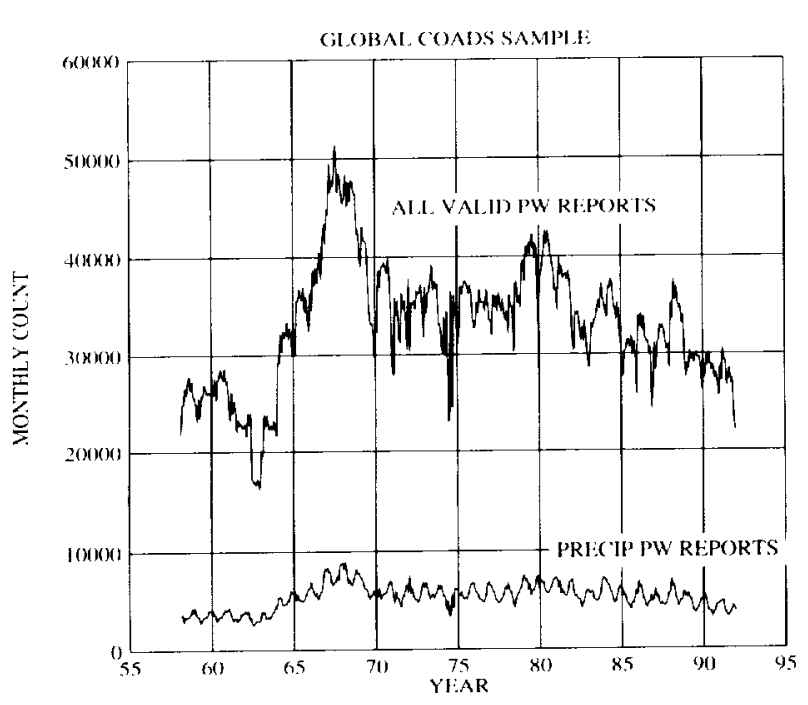

Fig. 2. Monthly count of global shipboard present-weather reports and precipitation reports used in the analysis.

and 2) the frequency of certain classes of precipitation reports relative to a more general class of precipitation. The first type of statistic may be interpreted as an absolute climatological frequency of a certain class of precipitation, while the second type may be interpreted as the predominance of a certain class of precipitation (e.g., snow) conditioned on the occurrence of a broader class (e.g., all precipitation).

\section{Results}

\section{a. Global statistics}

1) Reporting of PRECiPITATION

The 34-yr period of data analyzed yielded a total of $13.45 \times 10^{6}$ valid present-weather reports over the entire globe, of which $2.16 \times 10^{6}$, or $16.0 \%$, corresponded to one of the 66 precipitation codes appearing in Table 1. A time series of absolute counts per month is depicted graphically in Fig. 2. Of note here are substantial (up to a factor of $\sim 2$ ) fluctuations in the total sample size, with a minimum near 1963 and a maximum near 1967.

Figure 3 depicts the temporal dependence of the global fraction of reports representing precipitation. On a monthly basis, a pronounced annual cycle is seen that peaks in December and January and reaches a minimum in July. The magnitude and phase of this cycle is chiefly due to the overwhelming predominance of ship reports from the North Atlantic and North Pacific oceans, so that the unnormalized precipitation frequencies appearing in Fig. 3 reflect mainly the

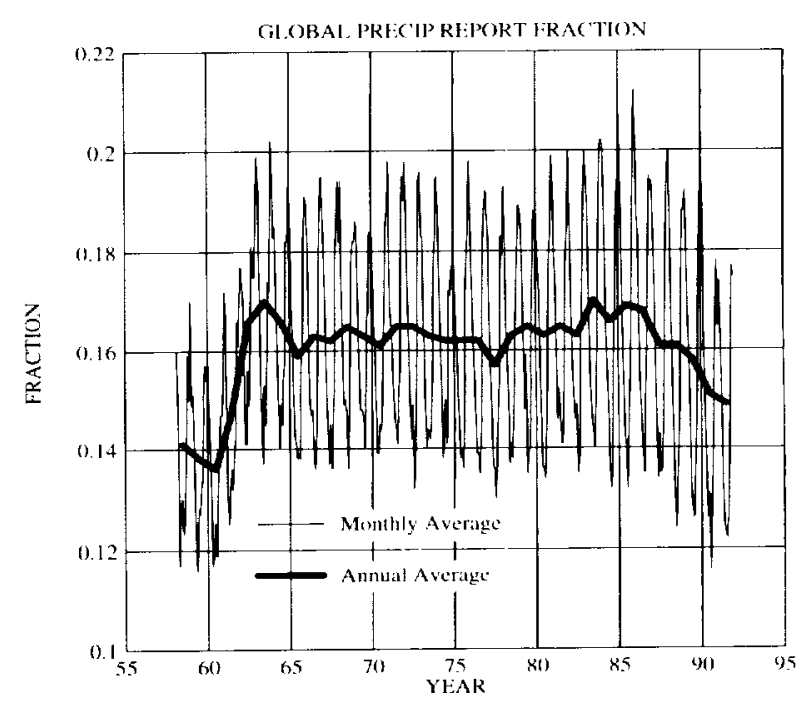

FIG. 3. Global fraction of valid present-weather reports indicating precipitation. seasonal cycle of precipitation in the northern middle latitudes.

An unexpected feature in Fig. 3 is a sharp increase (from $\sim 0.14$ to $\sim 0.16$ ) in the yearly average reporting of precipitation between 1960 and 1963 and a general downward trend again after about 1986. Candidate explanations for these differences include 1) systematic changes with time in the geographic or seasonal distribution of ship reports, 2) changes in shipboard present-weather reporting habits or procedures, 3) variations in the procedures for subsequent processing and reformatting of weather reports taken from ship logs, and/or 4) actual long-term trends in precipitation frequency. While the last of these hypotheses cannot be dismissed out of hand, it seemed prudent to first seek an explanation among the first three.

To examine the first possibility, separate time series of precipitation frequency were computed for each $10^{\circ}$ latitude-longitude box that always yielded a specified minimum number of reports per season over the entire 34-yr period. These were then averaged both in space and over the annual cycle so as to yield an areanormalized yearly average precipitation frequency. The resulting frequency curves (Fig. 4) do not differ appreciably from the unnormalized precipitation frequency, implying that large-scale geographic or seasonal shifts in the distribution of reports cannot be responsible for the sharp changes in the frequency of precipitation reports.

Regarding the second possibility, the only official change in reporting requirements known to the author 


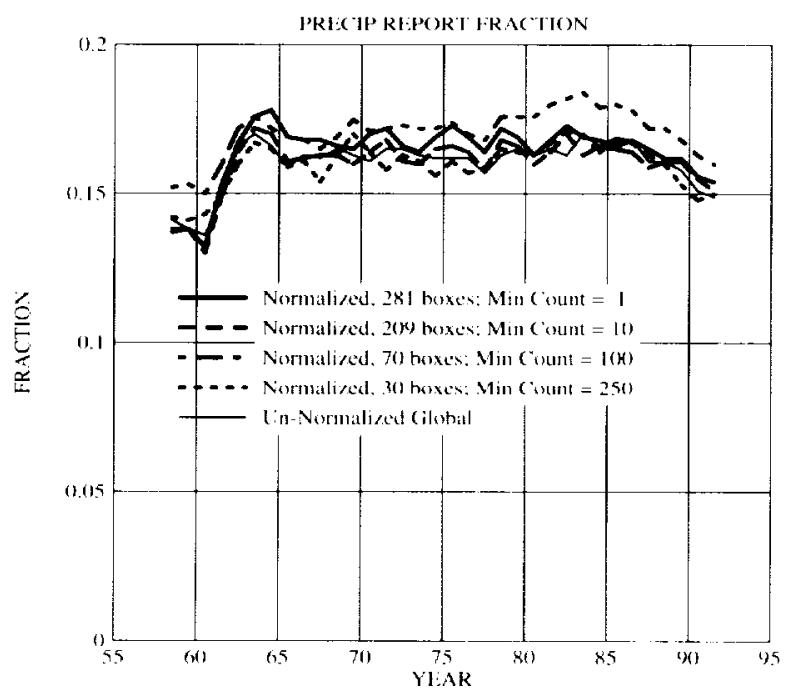

FIG. 4. Global fraction of valid present-weather reports indicating precipitation, calculated first as averages over season and over $10^{\circ}$ latitude-longitude boxes, and then combined to yield yearly global averages. Each curve corresponds to a different minimum seasonal sample size required in order for a latitude-longitude box to be included in the global average. The nonnormalized global fraction is reproduced from Fig. 3 for comparison.

to have been implemented during the period in question occurred in 1982, after which present weather could be coded as "missing" if there was no reportable weather. This year does not appear to be associated with a significant change in the reported frequency depicted in Fig. 4, though the downward trend beginning near 1987 might reflect a belated response by shipboard observers to the new rules. As noted earlier, an attempt was made to minimize the impact of the rule change by including only reports for which cloud information was reported.

The third alternative seems to be the most plausible of the possible explanations for the behavior of the precipitation frequency prior to 1964, as that year coincides with establishment of the international maritime meteorological exchange of ship logbook data in standardized formats under WMO Resolution 35. Earlier data were obtained in card decks in nonstandard formats from various countries and sources. Therefore, the apparent bias could possibly be an artifact of variations in processing and reformatting of original data to fit into the original card decks, or subsequent reprocessing to consolidate all the original card decks into the merged dataset that eventually was incorporated into COADS. An in-depth study of the data in each deck, and any surviving documentation, would probably be required to help answer this question more definitively (S. Woodruff and J. Elms 1995, personal communication).

The total relative uncertainty that the apparent bias, averaged over the full period, introduced into our results is of the order of $2 \%$. Consequently, the option of restricting the analysis to the shorter, but more homogeneous, period from 1964 to 1988 was rejected in favor of retaining the larger sample offered by the original 34-yr period.

2) Reporting of Ww codes and groups

Figures 5 and 6 , respectively, depict the total counts of each ww code (including nonprecipitating codes)

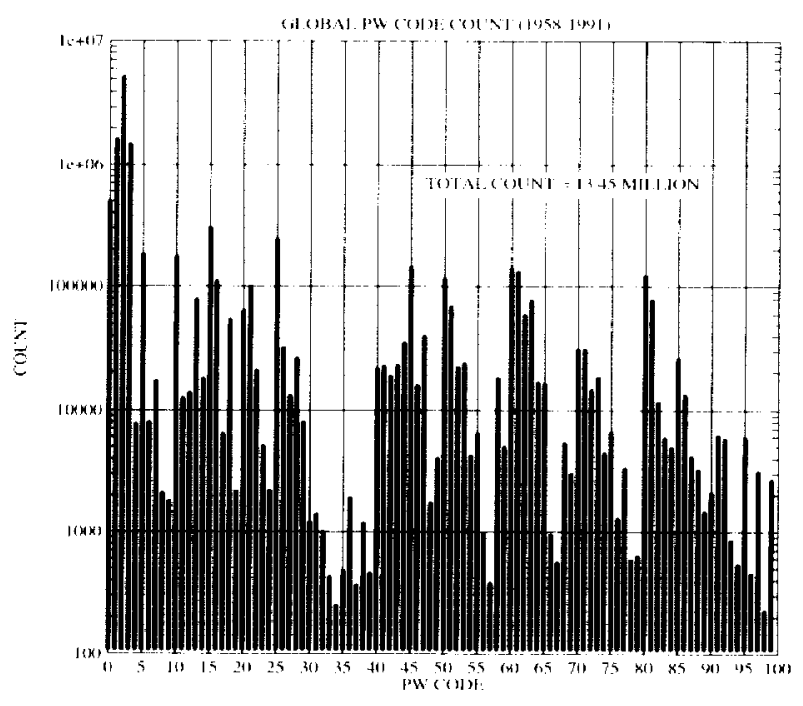

FIG. 5. Global histogram of all present-weather codes reported by ships during the period 1958-91.

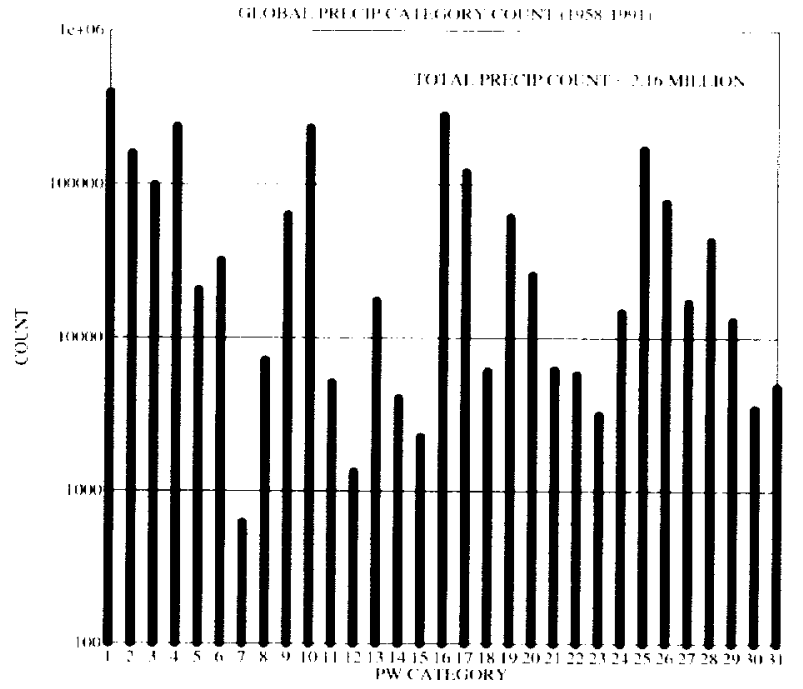

FIG. 6. Global histogram of the 31 present-weather categories defined in Table 3. 
and of each precipitation group encountered in this period. Apart from codes $1-3$, which imply the absence of any significant weather and which account for $61 \%$ of the total reports, the single most common code is 15 (precipitation observed at a distance but not at the station at the time of the observation; $2.98 \times 10^{5}$ reports or $2.2 \%$ of the total) followed closely by code 25 (rain at the station during the preceding hour but not at the actual time of observation; $2.41 \times 10^{5}$ reports or $1.8 \%$ ). The least common code, with a mere 222 reports, is code 98 , which represents the rare combination (at sea at least) of a thunderstorm and a dust storm or sandstorm at time of observation.

Of the precipitation groups defined in Table 3 , the most common, representing $18.8 \%$ of all precipitationrelated reports, is group 1 (Fig. 6). This group consists of all reports of precipitation within sight of, but not at, the station. Next, with $13.3 \%$, is group 16 , which consists of reports of light and steady or intermittent rainfall at the time of the observation. Group 4, corresponding to $w w=25$ (rain during the preceding hour), and group 10 (drizzle) follow with $11.2 \%$ and $11.0 \%$, respectively. Least common is group 7 (only 620 reports), representing sleet ( $w w=79$ ).

Combining groups based on intensity, character, or phase, it is found, for example, that $14.2 \%$ of the global precipitation reports correspond to drizzle-intensity precipitation (intensity class 1 ), while $16.1 \%$ correspond to moderate to heavy precipitation (intensity class 3 ). A total of $9.3 \%$ of the reports indicate snowfall in some form (phase class 2).

Finally, $9.2 \%$ of the precipitating reports represent ww codes indicative of thunderstorm activity or at least strong convection (character class 3 ), of which more than one-third $(3.6 \%$ of the total) are contributed by code 13 (lightning observed at a distance; no thunder), while another one-quarter $(2.5 \%$ of the total) are contributed by "squalls at or within sight of the station during the preceding hour or at time of observation" $(w w=18)$. [Note that the code definition does not make clear what constitutes a "squall" within this context. We have relied here on the "common nautical definition," as cited in Huschke (1959), of "a severe local storm considered as a whole, that is winds and cloud mass and (if any) precipitation, thunder and lightning."] The more narrow technical definition of a squall as a strong wind with sudden onset that persists for at most a few minutes seems inconsistent with the "within sight" aspect of the code 18 definition, since wind speed and duration cannot be reliably estimated at a distance by a shipboard observer.

\section{b. Regional frequencies of precipitation}

In this subsection, global maps of the absolute frequencies of occurrence of various classes of pre- cipitation relative to all valid $w w$ reports are presented. Although frequencies were tabulated at $2.5^{\circ}$ resolution, fields have been subsequently smoothed to $7.5^{\circ}$ resolution (or greater where indicated) for presentation purposes in order to reduce statistical noise in regions where the sampling is sparser. An unwanted side effect of this smoothing is of course that very localized features in the precipitation frequency, such as the intertropical convergence zone (ITCZ), appear somewhat flatter and more diffuse than they are in reality.

Figure 7 depicts the combined frequency of the 30 present-weather groups representing precipitation activity observed (or implied) at the surface; only group 13, virga, is excluded. Since this includes those codes representing precipitation occurring during the previous hour but not at the time of observation and those indicating precipitation within sight of the station, this figure may be loosely viewed as a map of the 1-h probability of precipitation at, or in the vicinity of, the station (note, however, that there are no ww code definitions corresponding to precipitation observed near the station during the previous hour). These frequencies range from less than $1.6 \%$ in certain portions of the subtropical dry zones to the west of the major landmasses to more than $25 \%$ in portions of the ITCZ, the South Pacific convergence zone (SPCZ), and at high latitudes. The monsoonal cycle is clearly evident in the Arabian Sea and the Bay of Bengal, as is a dramatic wintertime increase in precipitation frequency over the northern Pacific and Atlantic Oceans. During June-July-August (JJA), so few ship reports were received from the far southern latitudes that reliable frequencies could not be computed for much of this region.

Limiting the sample to the set of reports indicating precipitation actually observed at the station at the time of the observation (groups 7, 10-12, and 14-31), we obtain maps depicted in Fig. 8, which may be interpreted as depicting the approximate climatological frequency of precipitation at a single point in time and space. It is seen that the ITCZ is a less rainy place, at least in terms of precipitation frequency averaged over a $7.5^{\circ}$ grid box, than the far southern latitudes.

Not surprisingly, the instantaneous local precipitation frequencies in Fig. 8 are generally lower than the frequencies of nearby and/or recent precipitation depicted in Fig. 7. The fact that the ratio is regionally dependent is of some interest and will be considered again in the next subsection.

The patterns of rainfall frequency in Fig. 8 show some interesting differences from recent climatologies of annual or seasonal rainfall accumulation. For example, the map of mean annual precipitation by Legates and Willmott (1990) (not shown) depicts a very promi- 
(3) PROF of PRECIP VCNTY/PRFV HR (7.5 deg) for MAM (1958-:991)
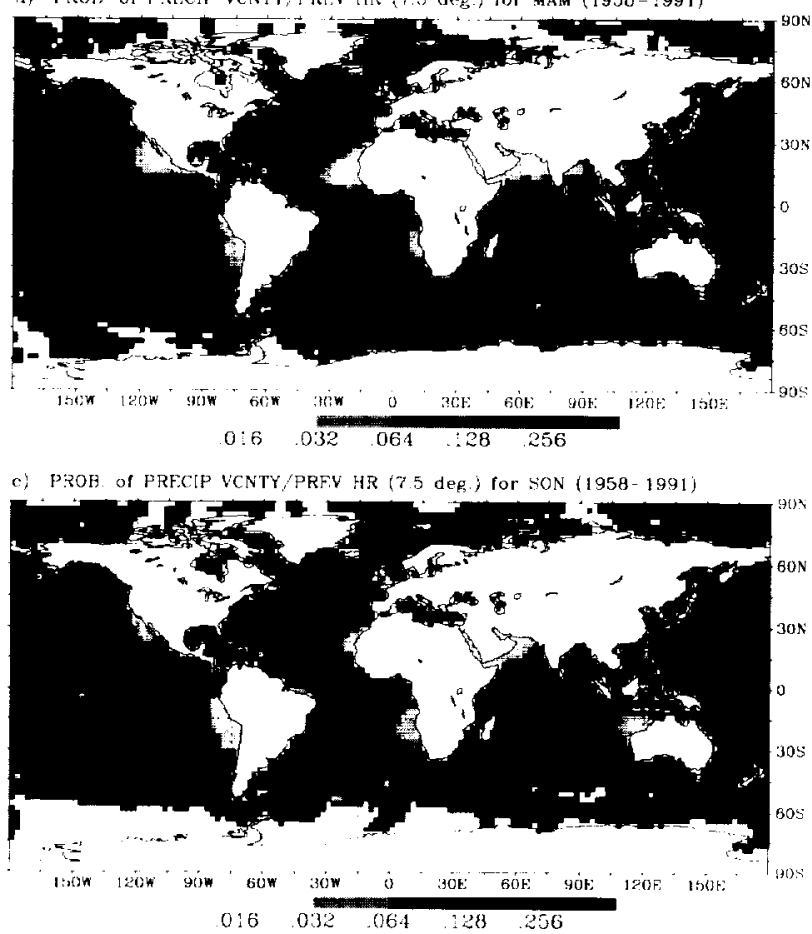

b) PROB. Of PREGIP VCNTY PREV 1'R (75 Heg) For JHA (1958 1991)

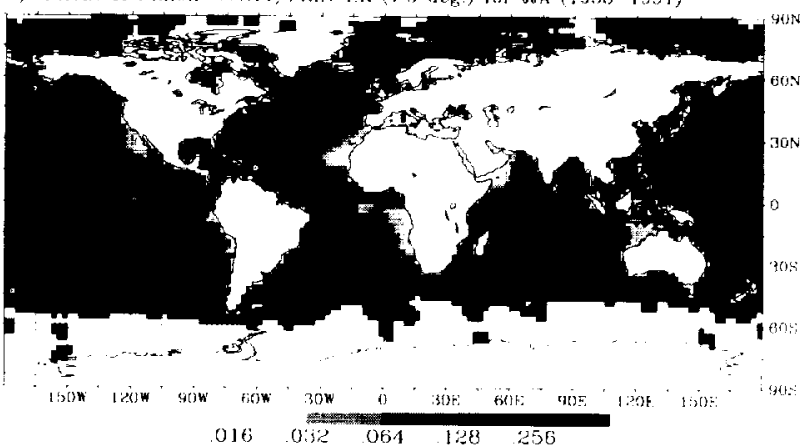

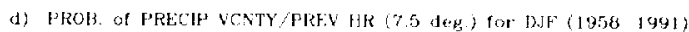

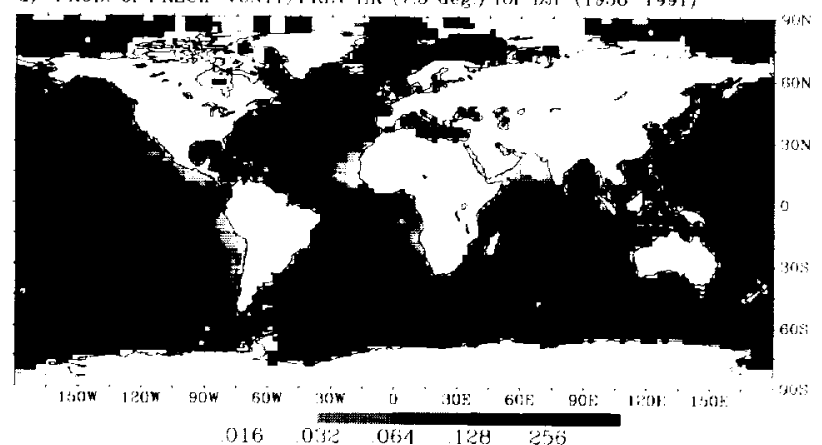

Fig. 7. Fraction of ww reports indicating some form of surface precipitation, either near or at the ship at the time of the observation or during the preceding hour. Displayed values at any geographic point are computed from ship reports within $7.5^{\circ}$ boxes centered on the point.

nent $1500-\mathrm{km}$-diameter "bulls-eye" of greater than $12 \mathrm{~mm}$ day $^{-1}$ embedded in the Pacific ITCZ near $140^{\circ} \mathrm{W}$. No analogous feature is observed in Fig. 8. Spencer (1993) too noted that this feature in the Legates and Willmott climatology was inconsistent with his own 14-yr rainfall climatology based on microwave sounding unit (MSU) observations. He attributed the discrepancy to the sparseness of surface ship data employed at that location in the Legates and Willmott analysis.

On the other hand, while the Spencer MSU-derived climatology (not shown) agrees quite well with Fig. 8 in the placement and shape of the ITCZ, there are important differences in the higher latitudes. In particular, the Spencer climatology depicts very pronounced, narrow "storm tracks" of enhanced rainfall extending eastward and slightly poleward across each of the midlatitude oceans. While the equatorward boundaries of his storm tracks have counterparts in Fig. 8, the poleward boundaries and the local maxima at the track centers do not. Rather, the COADS precipitation frequencies consistently increase more or less monotonically toward higher latitudes. As will be further discussed in section $4 \mathrm{~d}$, such differences between rainfall frequency patterns and mean rainfall accumulation can be reconciled only if it is assumed that there is a drastic reduction in the average precipitation intensity, within precipitation, poleward of the storm tracks.

Figure 9 depicts the climatological frequency of reports indicating strong convective activity and/or thunderstorms (character class 3 in Table 2; presentweather groups $2,15,18,24$, and 27). Not surprisingly, the highest frequencies are concentrated in the Tropics and subtropics along the ITCZ and SPCZ. Less expected, perhaps, are the relatively high frequencies $(>4 \%)$ appearing in the middle and high northern latitudes during the fall and winter seasons. It will be shown in a later subsection that the relatively high level of convective activity reported at high latitudes appears less dramatic when considered as a percentage of all precipitation reports.

\section{c. Zonal averages}

Figure 10 depicts the latitude-averaged frequency of all reports indicating "local or nearby surface precipitation" (i.e., all groups except 13, as in Fig. 7). Averages were obtained by first calculating seasonal frequencies on $2.5^{\circ}$ grid boxes and then averaging over longitude for ocean grid boxes containing a minimum of five valid reports. Similar calculations (Figs. 11-14, respectively) were done for "local pre- 

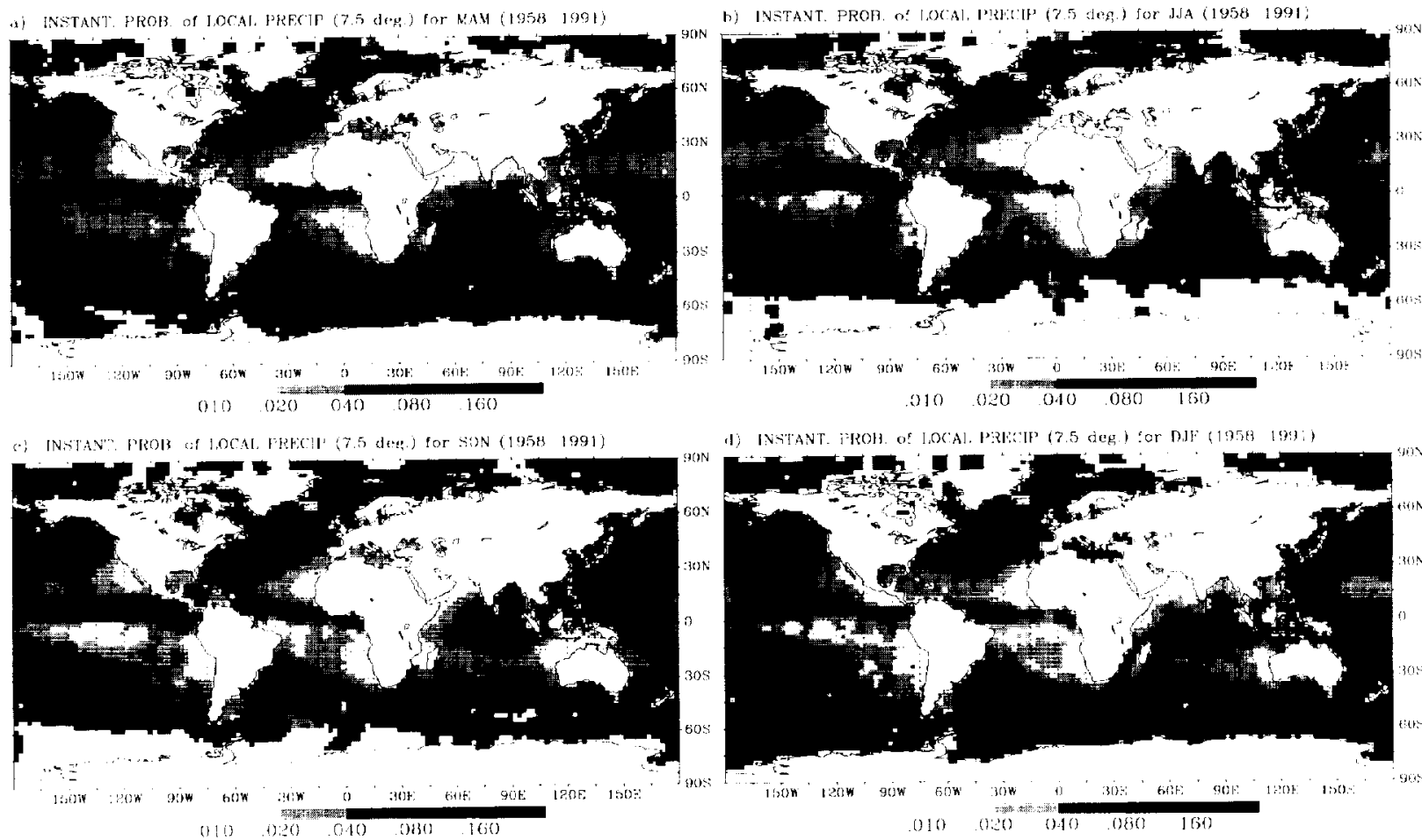

Fig. 8. Same as Fig. 7 but fraction of ww reports indicating some form of surface precipitation occurring locally and at the actual time of the observation.
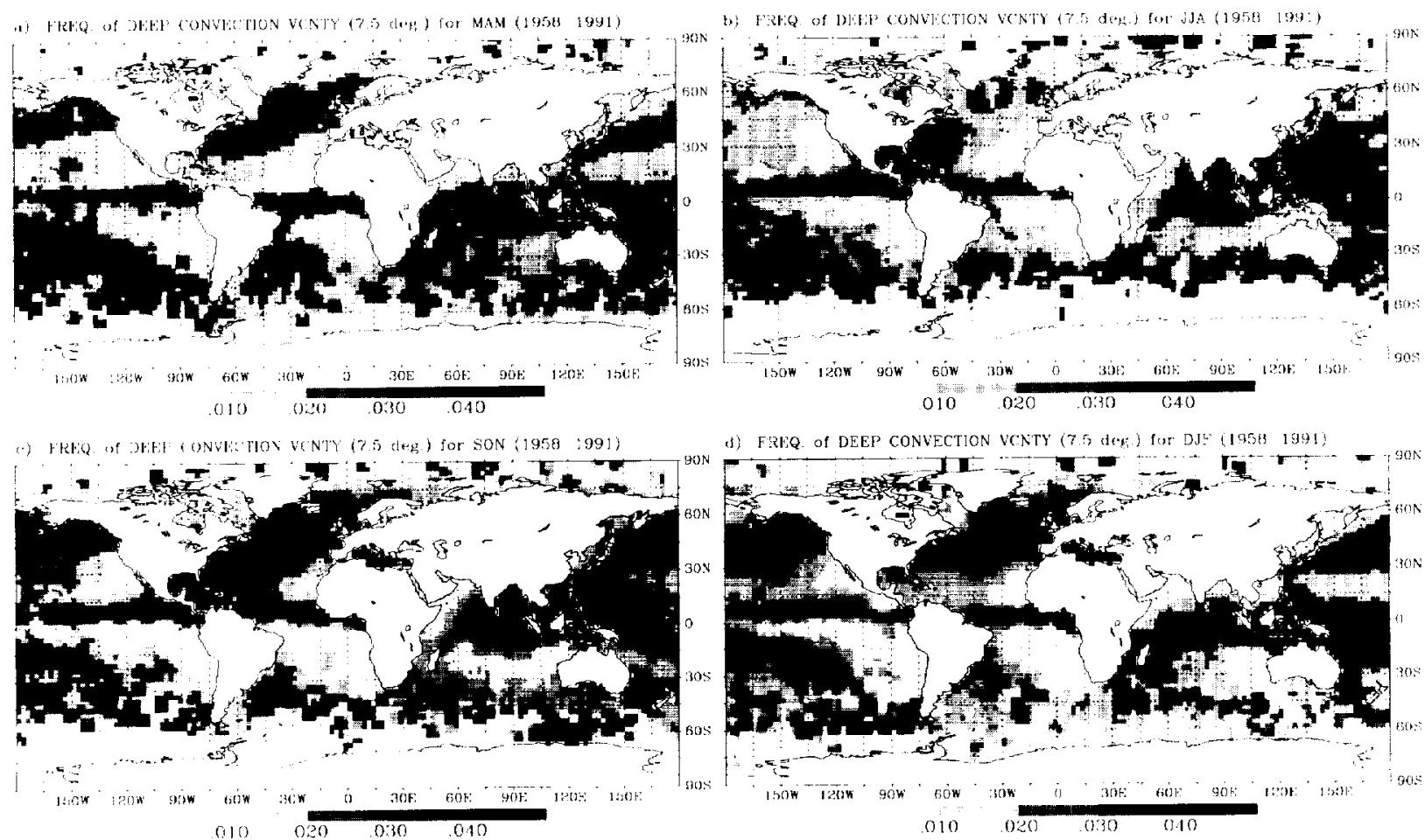

FiG. 9. Same as Fig. 7 but fraction of ww reports indicating some form of strong convective activity (character class 3 in Table 2 and Table 3). 


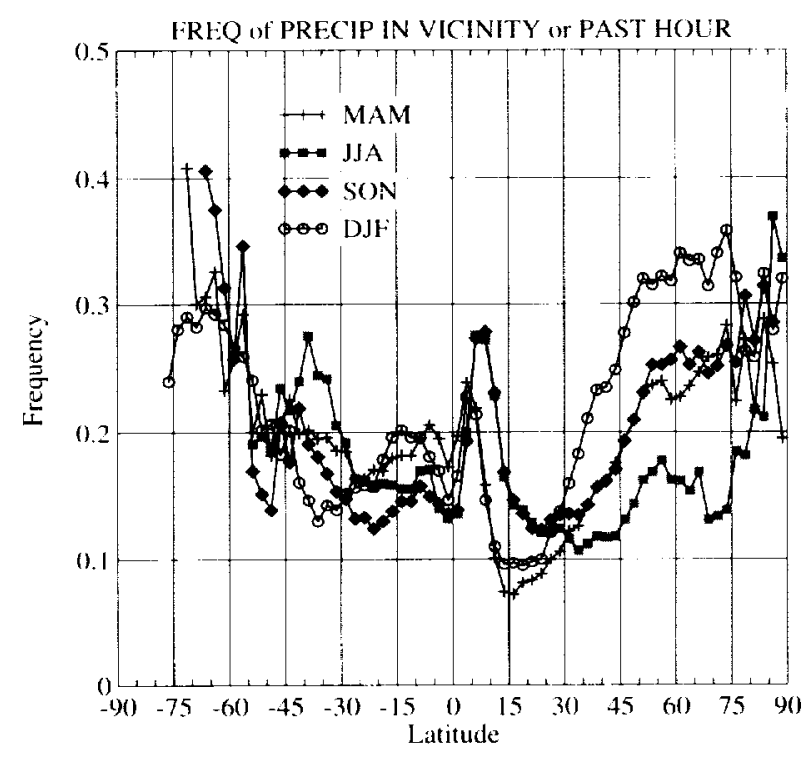

FIG. 10. Zonally averaged seasonal frequencies of reports indicating some form of surface precipitation, either near or at the ship at the time of the observation or during the preceding hour.

cipitation at the time of observation" (groups $7,10-12$, and 14-31; as in Fig. 8), "local precipitation of greater than drizzle intensity" (groups 7 and 14-31), "local precipitation of moderate or heavy intensity" (groups 23-31), and "deep convection in the vicinity" (groups $2,15,18,24$, and 27).

One interesting aspect of Figs. $11-13$ is the very high reported frequency of precipitation at high latitudes, with total instantaneous precipitation frequencies (Fig. 11) exceeding $20 \%$ at latitudes poleward of $60^{\circ}$. Even precipitation of moderate to heavy intensity (Fig. 13) is more likely to be reported north of $40^{\circ} \mathrm{N}$ during the winter months than anywhere else over the ocean, including the ITCZ belt. The latter statistic is perhaps less reliable than the first, however, since it depends on the ability of shipboard observers not only to note the occurrence of precipitation but also to classify its intensity according to reasonably consistent criteria. As discussed in section 2c, the subjective perception of intensity by an observer in any given instance may perhaps be biased by "typical" intensities experienced in a given climate zone.

Between the equator and $15^{\circ} \mathrm{N}$, the latitudinal distribution of precipitation is nearly identical for both the December-January-February (DJF) and March-ApritMay (MAM) periods; the JJA and September-October-November (SON) periods are likewise very similar. Among other things, these results suggest that, at a given latitude between $5^{\circ}$ and $15^{\circ} \mathrm{N}$, the annual cycle in oceanic rainfall peaks near August and September and is at a minimum near February and March, consis- tent with the expected influence of the monsoonal dry and rainy seasons over a substantial fraction of the tropical oceans. North of $35^{\circ} \mathrm{N}$, on the other hand, distributions are nearly identical for the fall and spring seasons, while the summer and winter seasons, not unexpectedly, represent opposite extremes in precipitation frequency.

In contrast to both of the above results, virtually no seasonal cycle in precipitation frequency is observed throughout most of the Southern Hemisphere. Hahn et al. (1995) found a similar lack of seasonal cycle in Southern Hemispheric cloud cover over the ocean, especially for daytime observations. While it is expected that the predominance of ocean area in the Southern Hemisphere would tend to moderate seasonal changes in baroclinicity relative to those in the Northern Hemisphere, there are nevertheless large seasonal variations in the mean air temperature over the Antarctic continent (and thus in the meridional temperature gradient offshore) as well as in the latitudinal extent of contiguous coverage by sea ice. That the reported precipitation frequency does not respond more markedly to these environmental differences is noteworthy.

Figure 14 depicts the frequency of reports suggestive of deep convective activity in the vicinity of the ship (groups 2, 15, 18, 24, and 27; as in Fig. 9). Unlike the precipitation frequencies discussed above, the frequency of deep convection tends to fall off toward high latitudes, though not as rapidly as one might expect. Frequencies in and near the ITCZ are only slightly higher $(\sim 5 \%)$ than those reported at $35^{\circ}-40^{\circ}$ during DJF $(4.4 \%)$. Also, in contrast to the precipitation frequency, there is significant seasonal variability in the frequency of convective activity in the southern tropical and middle latitudes. Interestingly, a sharp maximum is found in both hemispheres at identical latitudes $\left(37.5^{\circ}-40^{\circ}\right)$ during the respective winter seasons; the same latitudes are associated with a local minimum in convective activity during the summer seasons.

\section{d. Comparison with research ship observations}

As already noted, one notable aspect of the zonal average statistics computed above is the very high frequency of precipitation reported in the far southern latitudes. In particular, Fig. 11 shows average frequencies of local precipitation increasing monotonically from $\sim 7 \%$ near $30^{\circ} \mathrm{S}$ to $\sim 30 \%$ near $75^{\circ} \mathrm{S}$.

Published climatologies of mean annual precipitation accumulation tend to show a zonal maximum on the order of $1000 \mathrm{~mm} \mathrm{yr}^{-1}$ near $50^{\circ} \mathrm{S}$, with a decrease to approximately $\sim 500 \mathrm{~mm} \mathrm{yr}^{-1}$ (Legates and Willmott 1990) or even as little as $250 \mathrm{~mm} \mathrm{yr}^{-1}$ (Jaeger 1983) in the vicinity of $70^{\circ} \mathrm{S}$. For the frequency statistics 


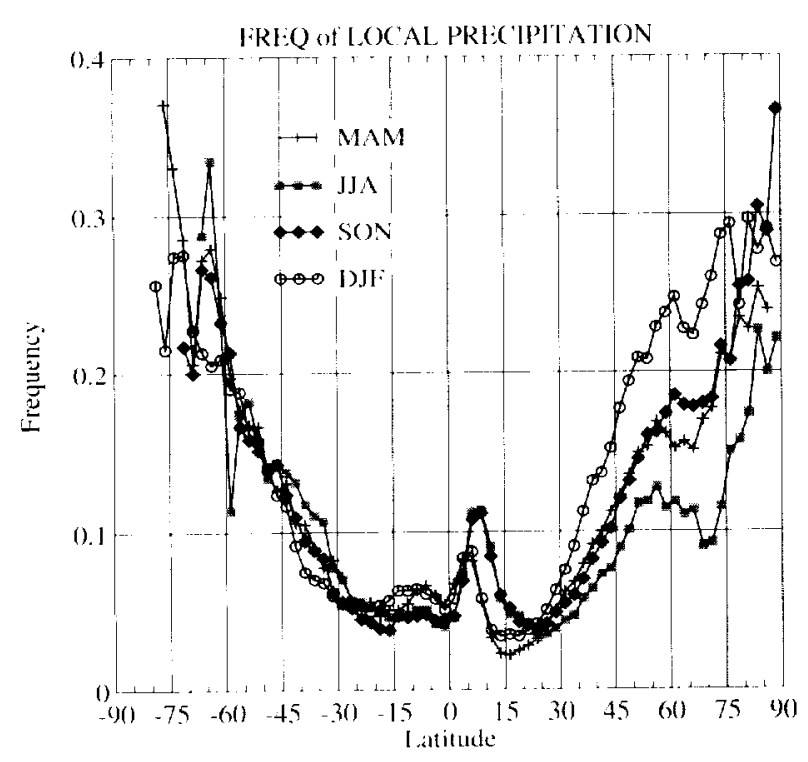

FiG. 11. Same as Fig, 10 but only ww reports indicating some form of surface precipitation occurring locally and at the actual time of the observation

presented here to be consistent with those climatologies, there would have to be a very sharp decrease toward the Antarctic coast in the average precipitation rate within precipitation. For example, if one accepts the Jaeger (1983) values, one must assume an average precipitation rate, within areas of precipitation, of $\sim 0.9 \mathrm{~mm} \mathrm{~h}^{1}$ at $50^{\circ} \mathrm{S}$, whereas the corresponding value at $70^{\circ} \mathrm{S}$ would only be $\sim 0.1 \mathrm{~mm} \mathrm{~h}$.

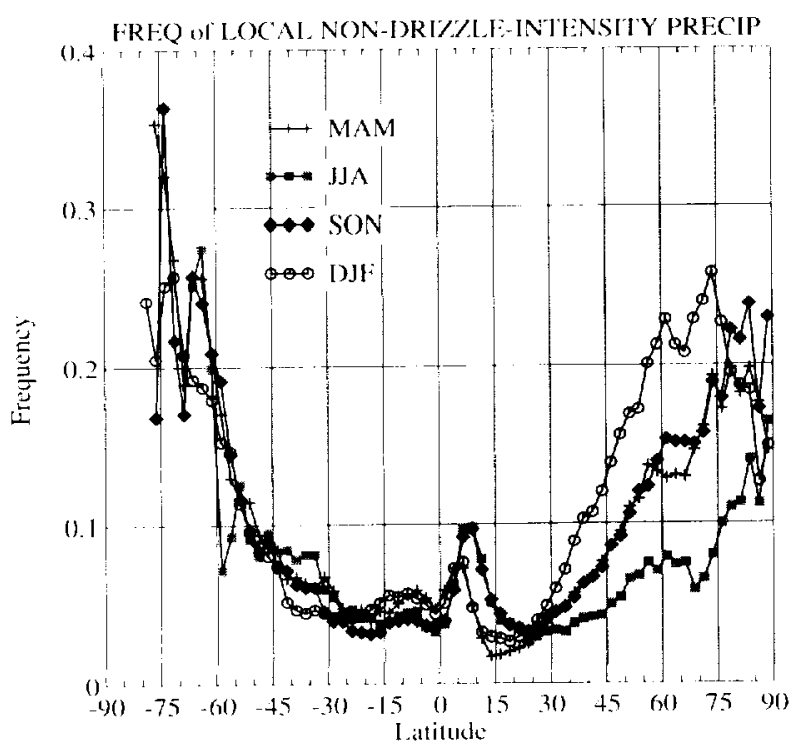

Fig. 12. Same as Fig. 11 but excluding precipitation of "drizzle" intensity (intensity class 1 in Table 2 and Table 3)
However, even the frequency of moderate to heavy precipitation derived from the COADS reports increases sharply toward Antarctica (Fig. 13), with values as high as $\sim 6 \%$ in the vicinity of $70^{\circ} \mathrm{S}$. If one conservatively assumes a minimum intensity of $\sim 1.0 \mathrm{~mm} \mathrm{~h}$ : (equivalent to $\sim 1 \mathrm{~cm} \mathrm{~h}^{-1}$ snow accumulation) associated with this class of report and one ignores the contribution from light precipitation, the resulting lower bound on the mean annual precipitation at that latitude is still $\sim 500 \mathrm{~mm}$ or greater. Including the contribution from light snow and/or using a threshold for moderate precipitation more in line with the nominal threshold of $2.5 \mathrm{~mm} \mathrm{~h}{ }^{1}$ would significantly increase the total.

One must therefore either conclude that total precipitation is more abundant in the far southern latitudes than is indicated in previously published climatologies or else that there are large systematic biases in the reporting of precipitation frequency and/ or intensity at those latitudes by ships of opportunity. To investigate the latter possibility, weather logs were obtained from a South African scientific research vessel, the S.A. Agulhas, which made several voyages between South Africa and an Antarctic coastal station during January 1991-May 1993. The locations and seasonal timing of the Agulhas' weather observations are indicated in Fig. 15.

It is expected that weather observations taken regularly at 3-h intervals onboard a scientific research vessel are less likely to suffer from systematic reporting biases of the type discussed in section 2c than are the sometimes intermittent observations from the

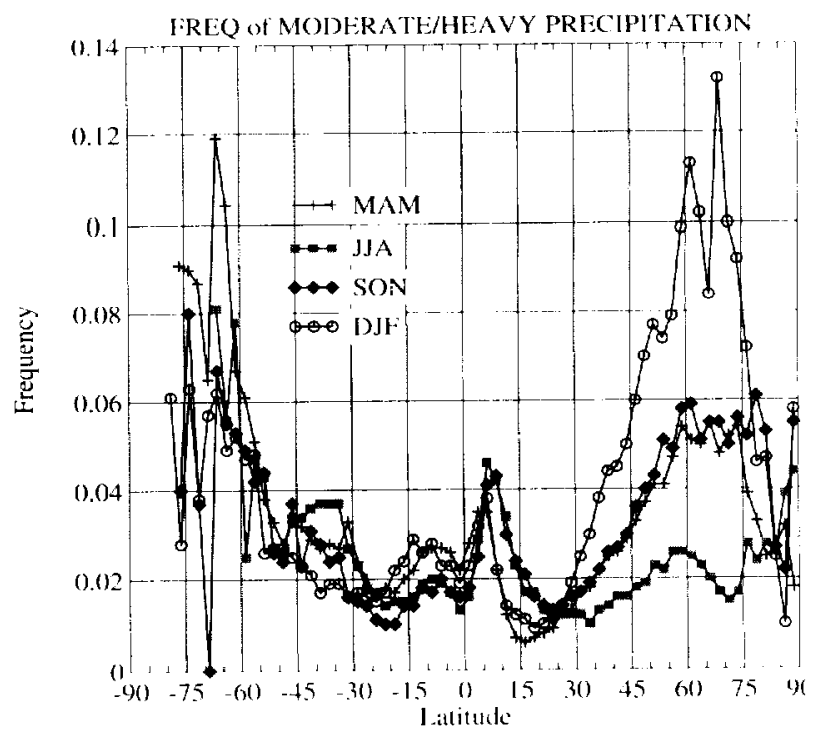

FIG. 13. Same as Fig. 11 but including only precipitation of moderate or heavy intensity (intensity class 3 in Table 2 and Table 3 ). 


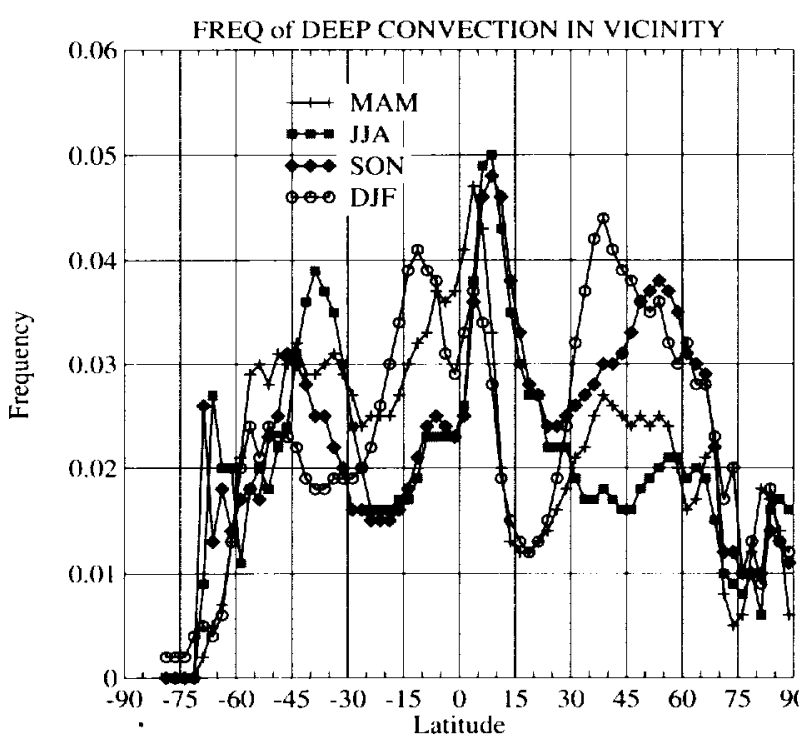

FIG. 14. Zonally averaged seasonal frequencies of reports indicating strong convective activity (character class 3 in Table 2 and Table 3).

merchant or fishing vessels that constitute the majority of COADS reports. It is therefore noteworthy that the summary statistics of the S.A. Agulhas' precipitation present-weather reports for $5^{\circ}$ latitude intervals (Fig. 16) are in excellent agreement with the corresponding COADS statistics presented in Figs. 11-13, notwithstanding significant statistical uncertainties in the Agulhas' precipitation frequencies (especially for moderate/heavy precipitation) due to the small sample.

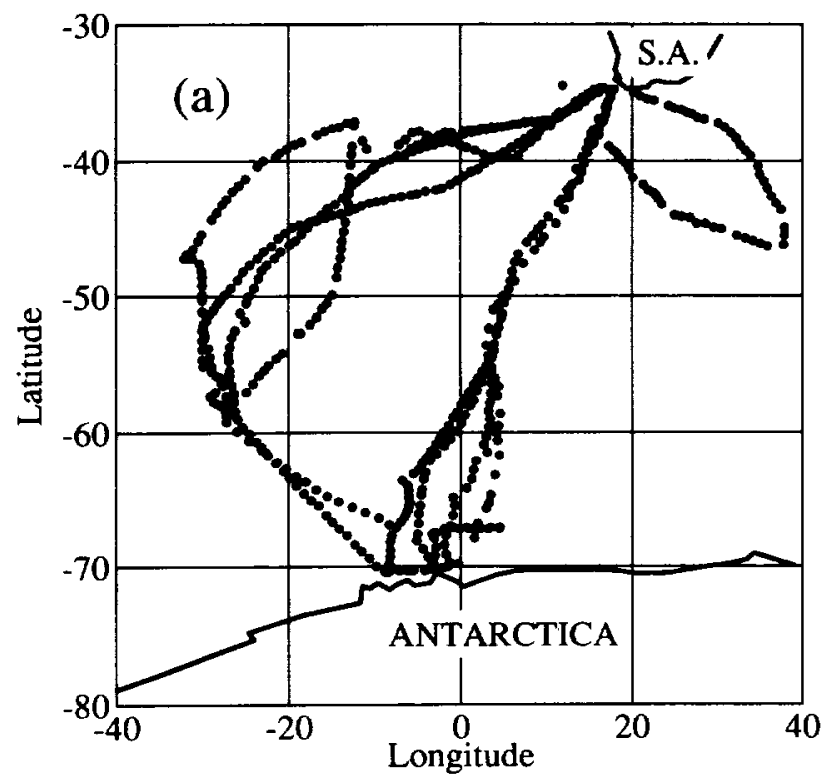

There thus appears to be no immediate basis for discounting as biased the rather high COADS-derived precipitation frequency statistics for this latitude belt.

\section{e. Regional characteristics of precipitation}

When absolute frequencies of various types of oceanic precipitation are globally mapped as in section $4 \mathrm{~b}$, only relatively subtle variations in global patterns can be discerned, since the shapes of these patterns are all dominated by the rather dramatic differences in overall precipitation frequency that distinguish the subtropical highs from the ITCZ, SPCZ, and midlatitude storm tracks. New spatial patterns, and new insight into the regional characteristics of precipitation, emerge when the frequency of a selected class of precipitation report is expressed as a fraction of the frequency of a more general class that includes the first class as a subset. There is a very large number of possible combinations of groups that can be considered; space permits only a few of the more interesting examples to be presented here.

1) INTENSITY

Figure 17 depicts the fraction of all surface precipitation reports, excluding those of indefinite intensity (i.e., intensity code 0 in Table 3), that specifically indicate precipitation of extremely light or "drizzle" intensity (groups 9-12 only). Globally, a typical value for this ratio is approximately $20 \%-30 \%$; slightly smaller values prevail throughout much of the tropical belt.

A few regions, however, show a decided preference $(>50 \%)$ for drizzle-intensity precipitation relative

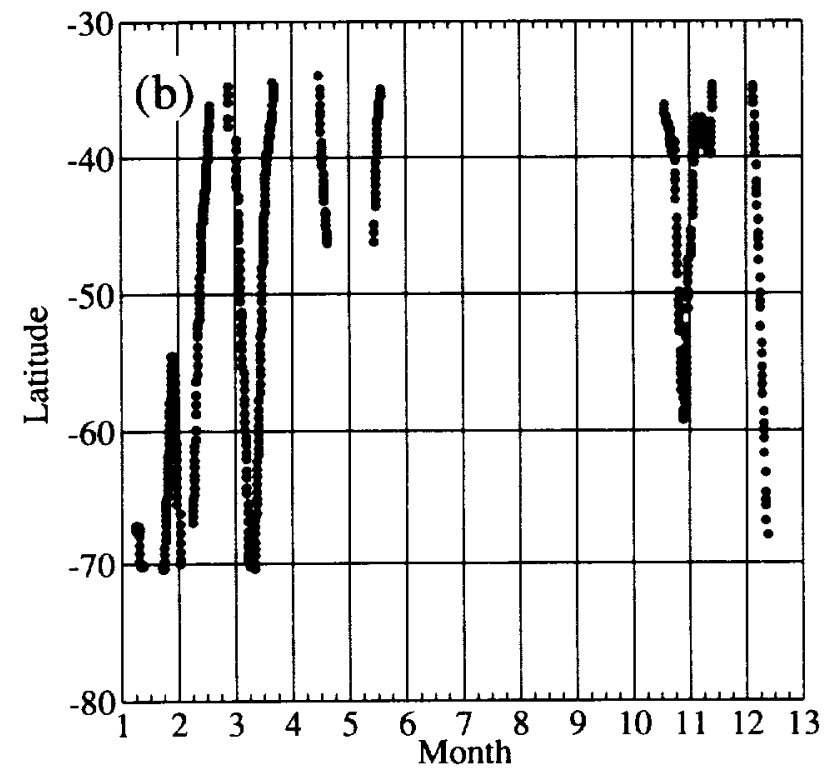

FIG. 15. Location and timing (with respect to time of year) of 3-h weather observations obtained from the South African research ship S.A. Agulhas. (a) Geographic location; (b) latitude vs time of year. 
to other forms. One prominent region encompasses most of the Pacific north of $30^{\circ} \mathrm{N}$ during June-August. Others correspond to known regions of persistent coastal marine stratocumulus clouds arising from a combination of cool sea surface temperatures and subsiding air within the subtropical high pressure belts; the most prominent of these are found off the west coasts of North America and South Africa.

Less well documented is a narrow but pronounced tongue of high drizzle fraction appearing just south of the equator and west of South America during the months of June-November. Both the seasonality and location of this climatological feature is consistent with low-level stratocumulus formation as air blows northward over the tongue of cooler sea surface temperatures on the south side of the equatorial front (Deser et al. 1993).

The very low drizzle fraction $(<15 \%)$ appearing at very high latitudes probably reflects the fact that even extremely light frozen precipitation is more likely to be reported as light snow (codes 70 and 71 ) than as ice prisms (code 76), snow grains (codes 77), or isolated snow crystals (code 78).

Figure 18 depicts the frequency of moderate or heavy precipitation (intensity class 3 ) conditioned on the occurrence of precipitation of at least light intensity (intensity classes 2 and 3 combined). The frequency of drizzle intensity precipitation is not included in the denominator of this ratio, because true drizzle is normally produced by meteorological and microphysical processes quite distinct from those responsible for the other forms of precipitation.

As before, significant regional differences are apparent, though the details of these differences are more difficult to relate to known climatological features. For example, there is a decided tendency $(>50 \%)$ for precipitation to be reported as moderate to heavy in intensity in the vicinity of Indonesia, near the southwest coast of North Africa, and between Africa and Madagascar, even relative to other tropical areas. A similar tendency exists during the spring and summer months over the northern Indian Ocean.

By contrast, less than $20 \%$ of rain reports in regions near the California and West South Africa coasts are classified as moderate to heavy. While this may partly reflect a genuine predominance of light rain, when rain occurs, the geographic distribution raises the possibility that many of the nominal light rain reports in these areas actually represent misclassified drizzle (cf. Fig. 17).

\section{2) PHASE}

Figure 19 depicts the frequency of snow reports (phase category 2) expressed as a fraction of all precipitation reports for which phase is indicated. The
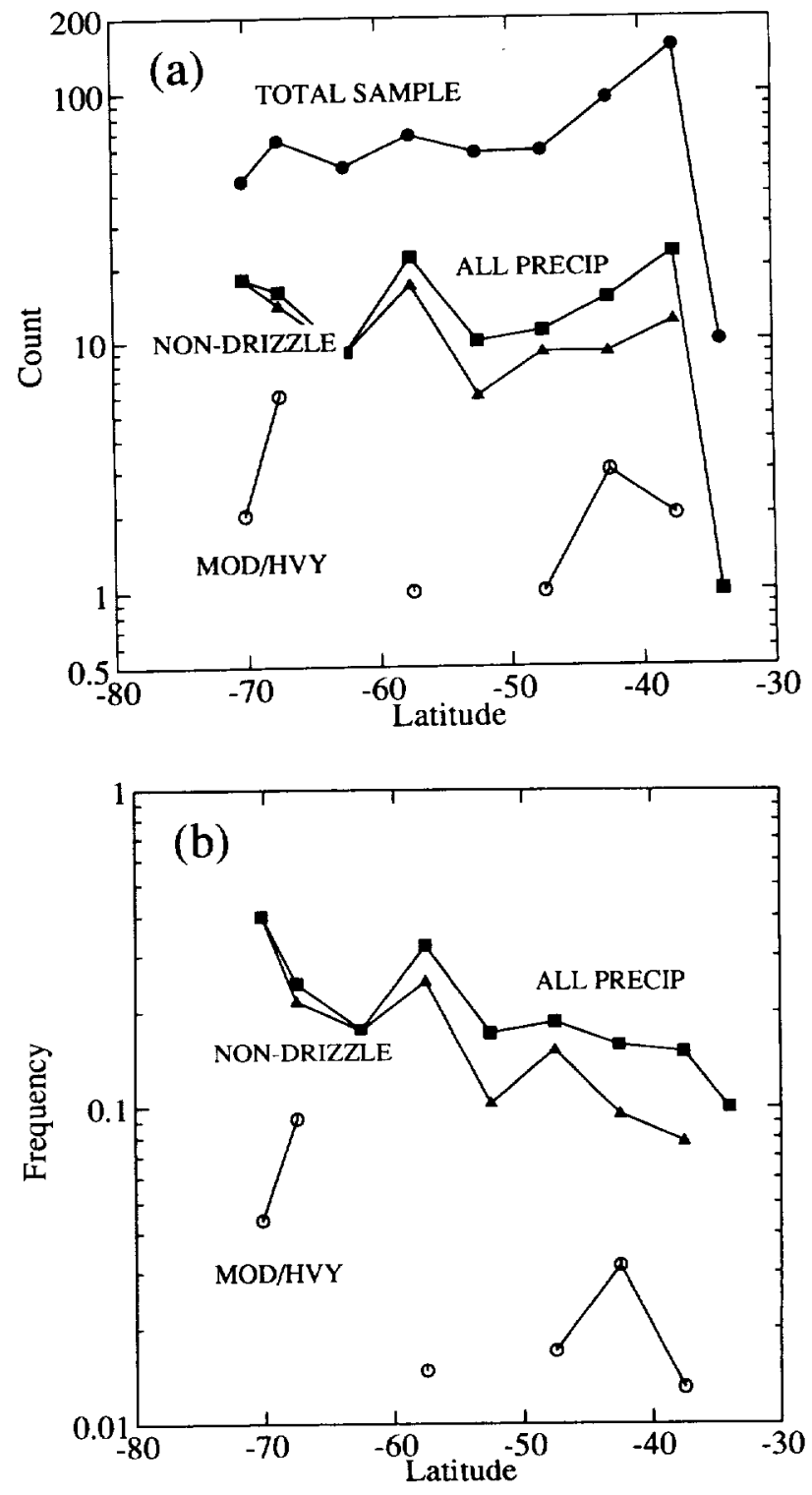

FIG. 16. Precipitation statistics derived from the S.A. Agulhas. (a) Total counts of ww reports falling in various intensity categories; (b) normalized frequencies derived from the counts in (a).

seasonal shift in the snow line is clearly discernible in the Northern Hemisphere, while it is considerably less dramatic in the Southern Hemisphere. Indeed, the northernmost boundary of occasional snowfall at approximately $30^{\circ} \mathrm{W}$ appears to be fixed very close to $45^{\circ} \mathrm{S}$, irrespective of season.

In addition to shedding light on the seasonal boundaries between predominantly liquid and predominantly solid surface precipitation, the qualitative reasonableness and smoothness of the patterns, even in datasparse regions, would appear to rule out a significant contribution to the statistics by mislocated reports. The only apparent anomalies are a number of nonzero 


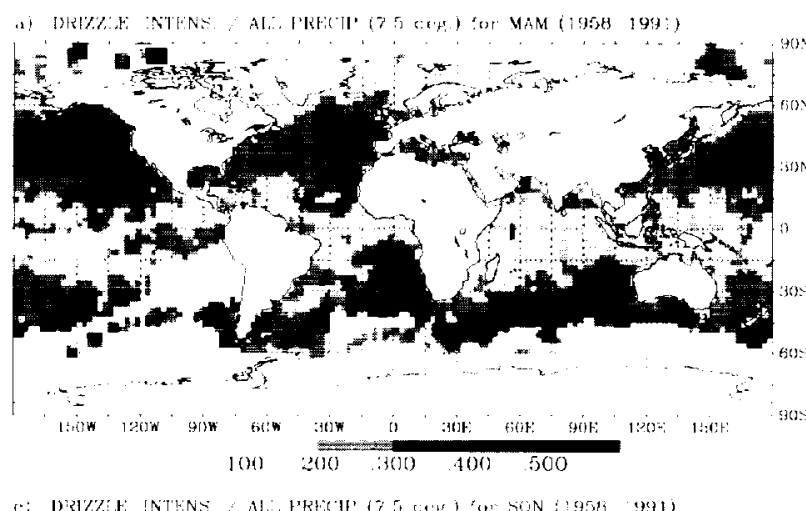

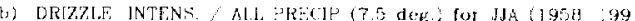
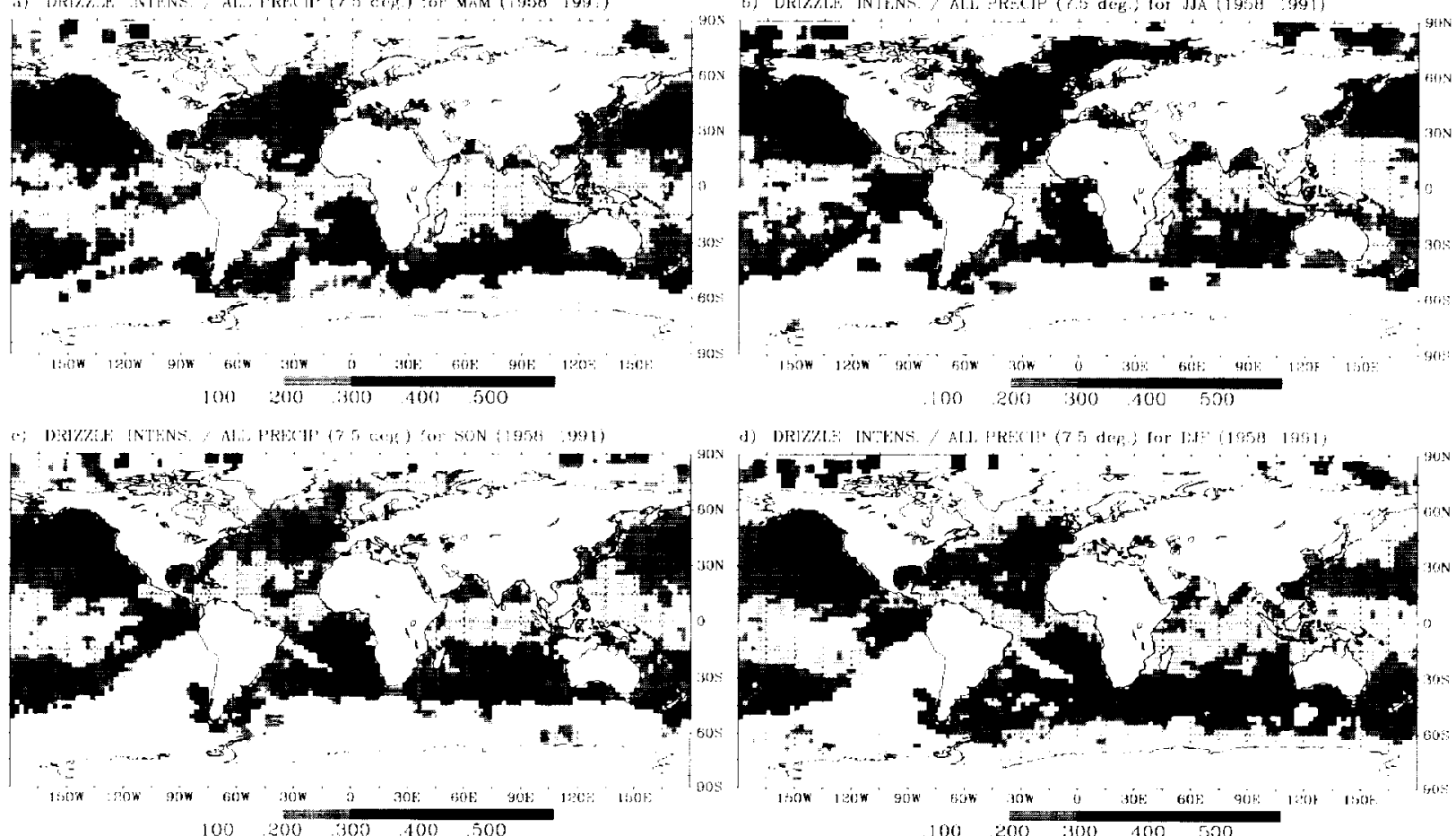

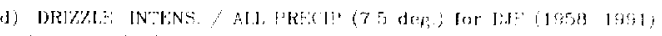

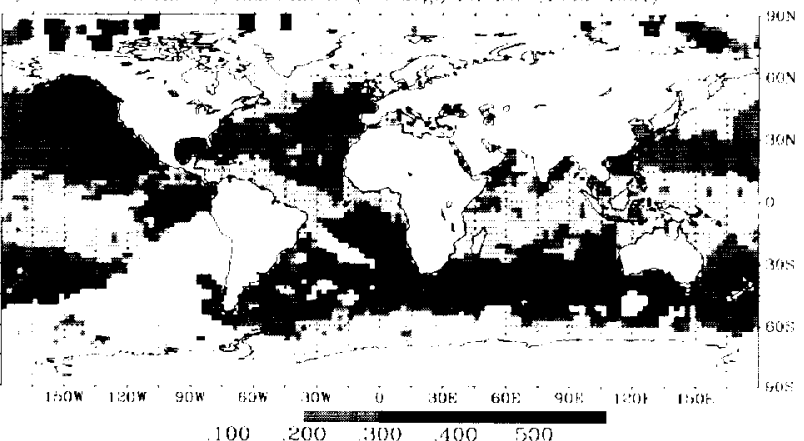

FIG. 17. Fraction of all surface precipitation reports specifically associated with "drizzle" intensity precipitation (intensity class 1 in Table 2 and Table 3).

values for snow fraction appearing at certain lowlatitude locations, especially along the African, Arabian, and Indian coasts. One preferred location is at the intersection of the equator and Greenwich Meridian, suggesting that zeroes have been substituted for the correct latitude and longitude in a number of reports. Other anomalies, such as those at the mouth of the Persian Gulf and at $15^{\circ} \mathrm{S}, 10^{\circ} \mathrm{E}$ in MAM and SON, are harder to explain, especially given the relatively high density of legitimate ship reports at those locations.

3) Strong convection and thunderstorms

Figure 20 depicts the frequency of $w w$ reports indicative of thunderstorms or strong convective activity (character class 3 ) expressed as a fraction of the frequency of all reports of precipitation, excluding intensity class 1 (drizzle). This depiction of the relative predominance of strong convective activity reveals some surprisingly pronounced regional variations.

In particular, the highest rates of thunderstorm or squall activity appear to be confined to several welldefined zones in which such reports constitute $>24 \%$ of the total nondrizzle precipitation reports, as contrasted with roughly half that value at many other locations in the Tropics and subtropics. Furthermore, these zones of high activity appear to be closely tied to the continents and to vary only in relatively minor ways from one season to the next. Even within the Atlantic and Pacific ITCZ, the tendency for thunderstorms, lightning, or squalls to be reported depends rather strongly on proximity to land.

Some similarities are apparent between the reported patterns of thunderstorm/squall activity and the tendency for heavier rainfall to be reported (cf. Fig. 18) - both maps, for example, are fairly consistent in depicting higher fractions near Indonesia, over the northern Indian Ocean, and near Central America and West Africa. However, the regions of high-reported convective activity in Fig. 20 appear more coherent and sharply delineated.

As noted in section 4a, the inclusion of "squalls at or within sight of the station" $(w w=18)$ introduces some uncertainty in the meteorological interpretation of the above statistics, since this code contributes a significant fraction of the global reports falling in character class 3 , yet its reporting criteria are probably among the least well understood by shipboard observers (based in part on the author's own experience as a shipboard observer in the U.S. Navy). To specifically examine the relative frequency of thunderstorm activity, the COADS dataset was reanalyzed, this time 

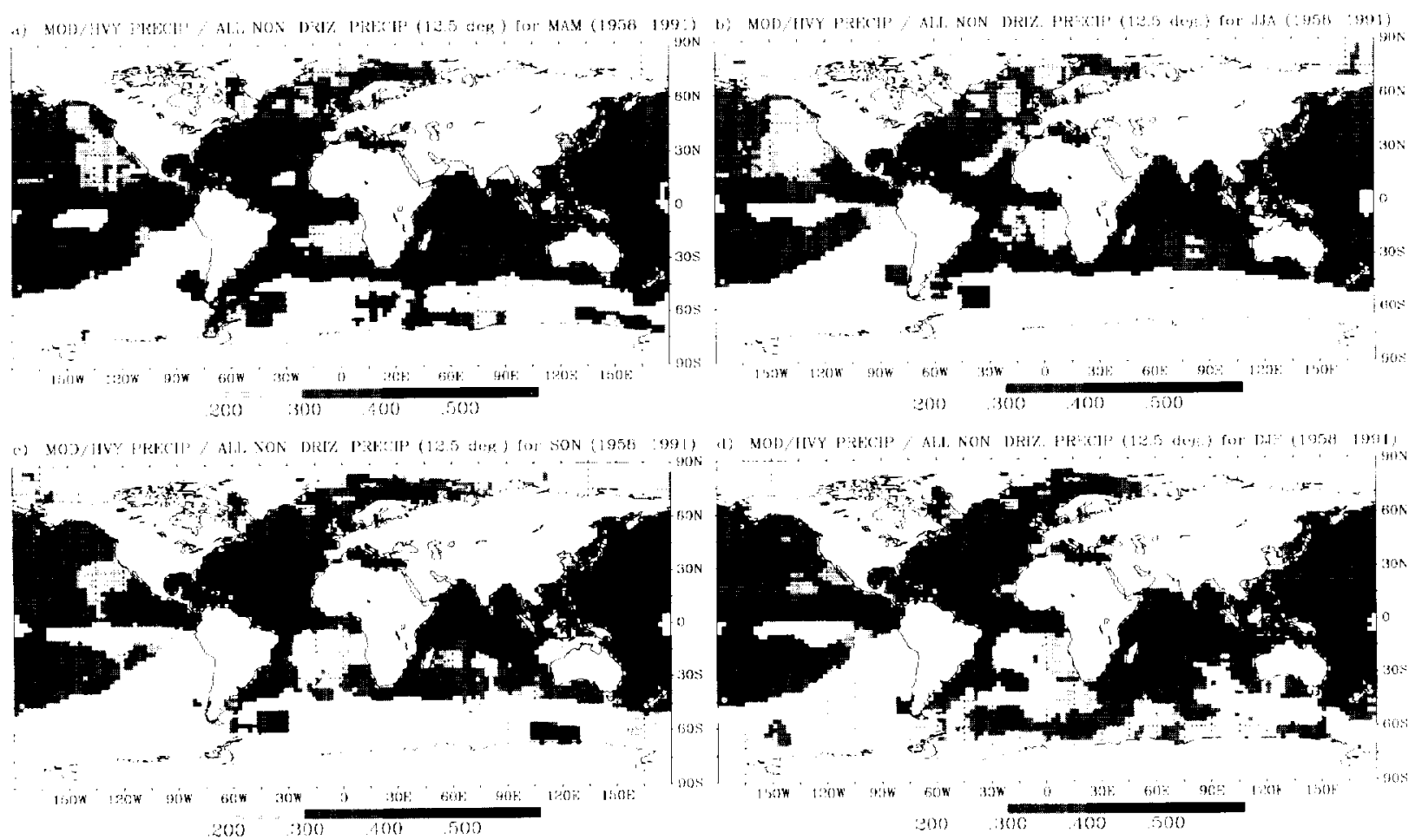

FIG. 18. Fraction of all surface precipitation reports specifically associated with "moderate or heavy" intensity precipitation (intensity class 3 in Table 2 and Table 3). Displayed fractions are calculated from reports within $12.5^{\circ}$ latitude-longitude windows centered on each $2.5^{\circ}$ grid box.
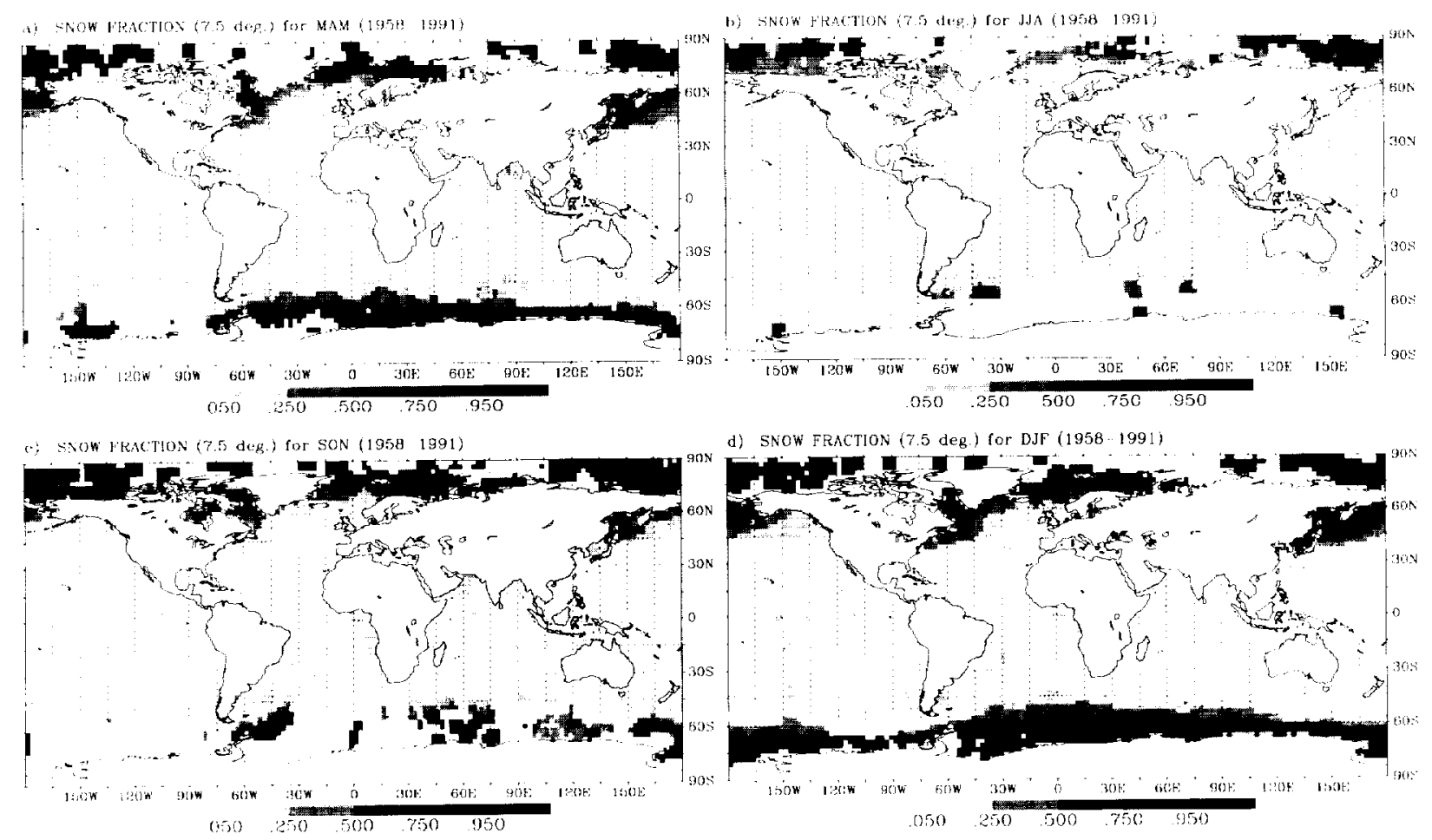

FIG. 19. Fraction of all surface precipitation reports specifically associated with "snow"(phase class 2 in Table 2 and Table 3 ). 

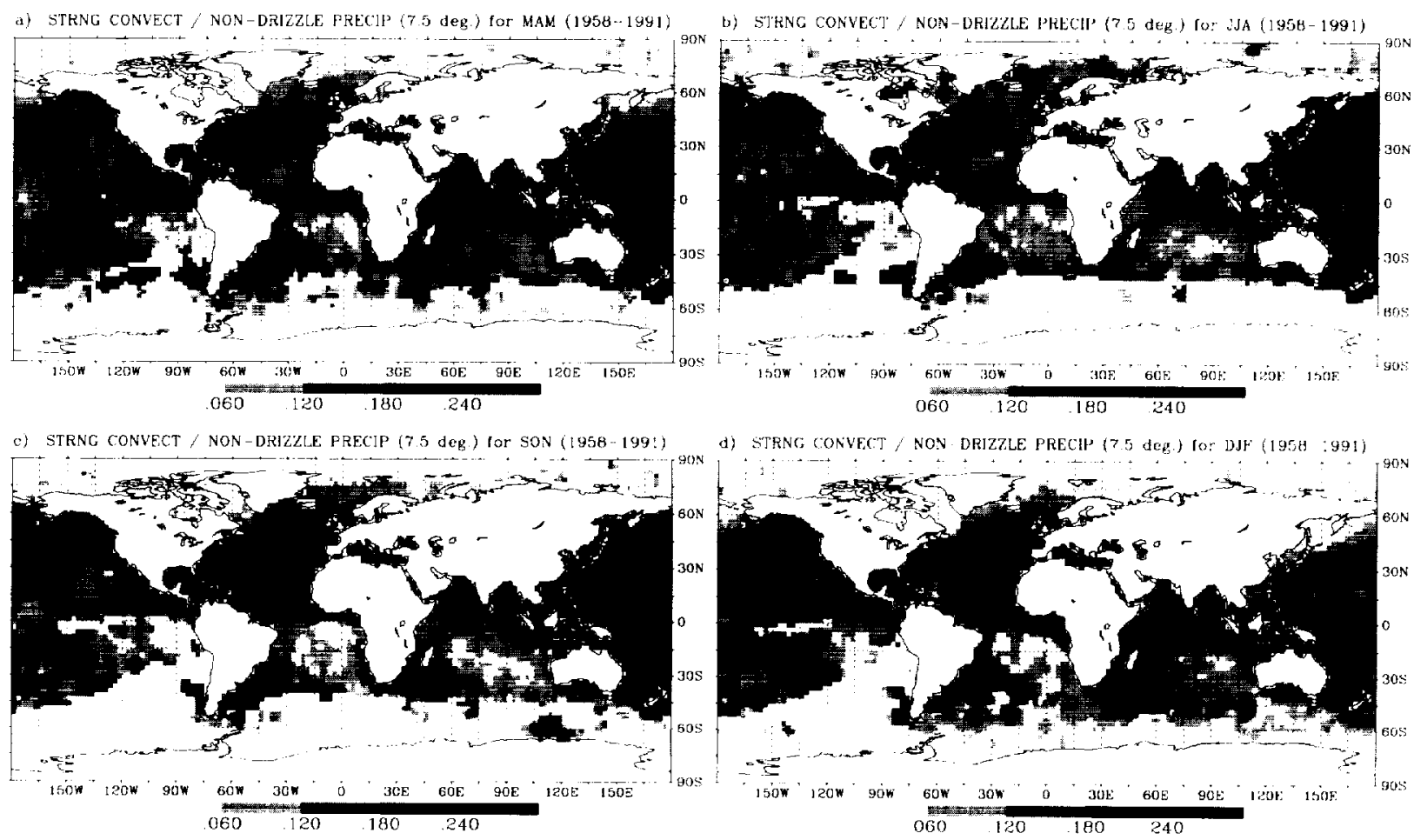

FIG. 20. Fraction of all nondrizzle surface precipitation reports (i.e., excluding intensity class 1) specifically associated with strong convection or thunderstorms (character class 3 in Table 2 and Table 3 ).
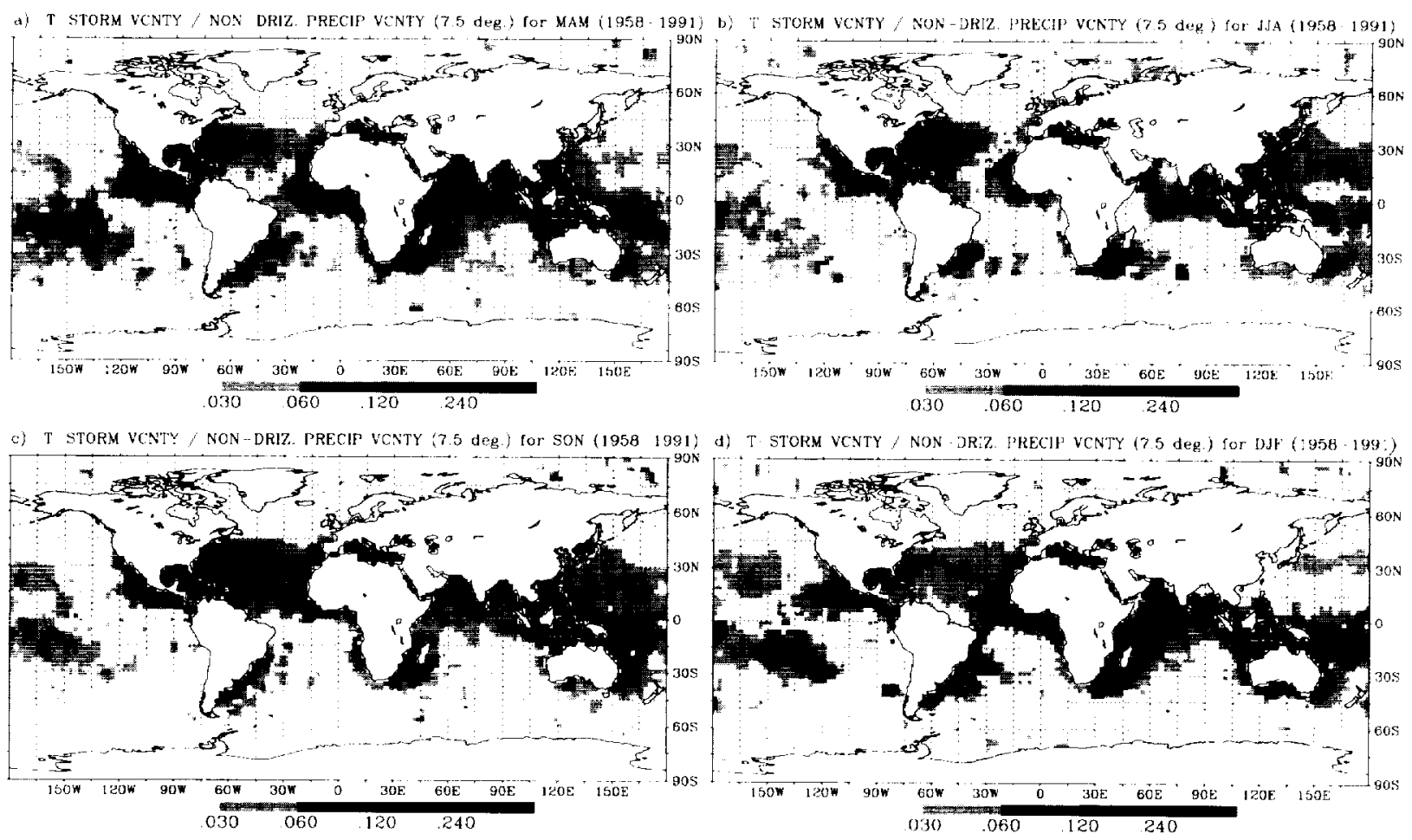

FIG. 21. Same as Fig. 20 but excluding $w w=18$. Note use of logarithmic scale. 

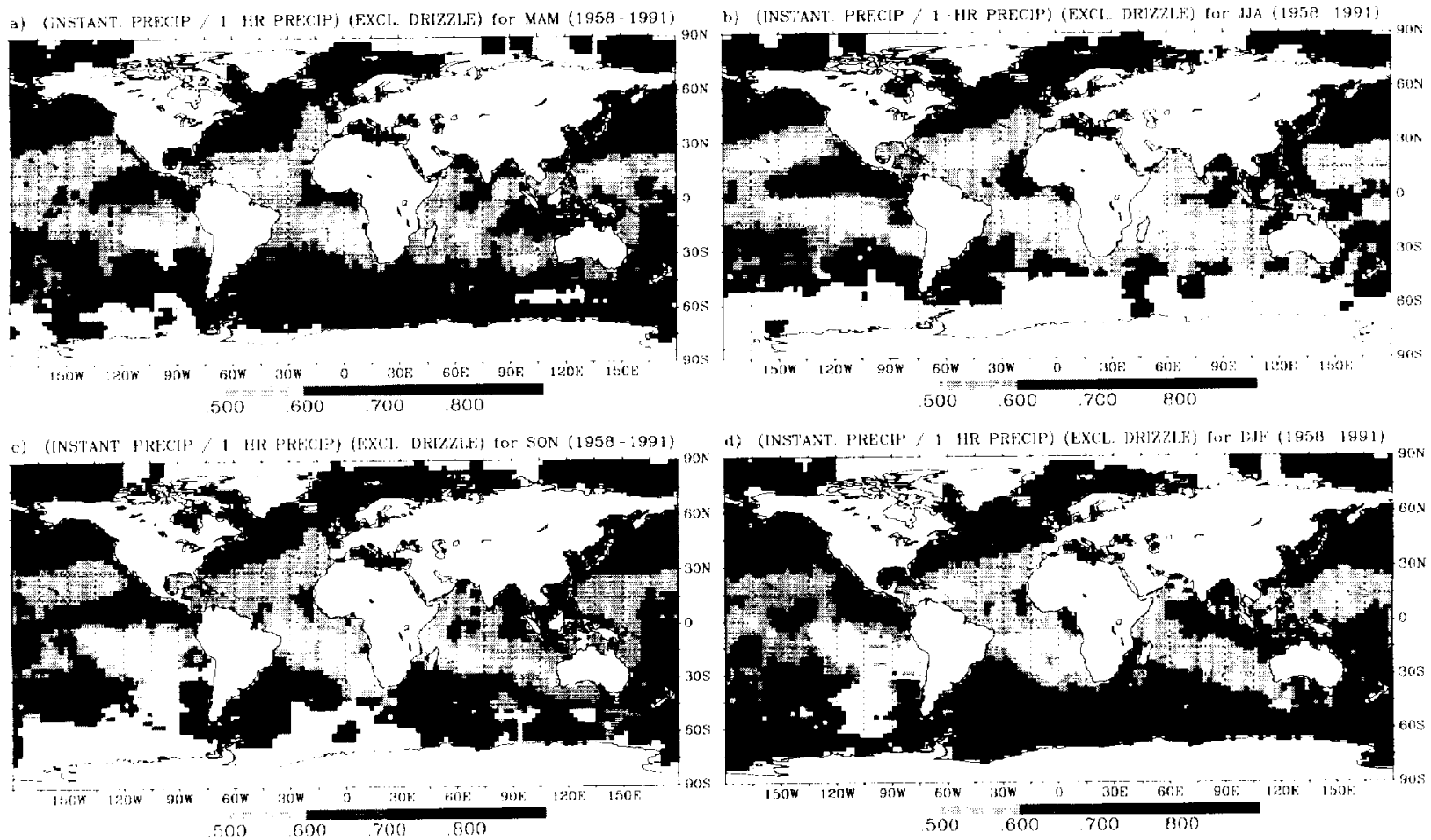

FIG. 22. Frequency of local nondrizzle precipitation occurring at the time of the observation, expressed as a fraction of all nondrizzle precipitation reports, including precipitation during the preceding hour. Low values of the ratio imply a predominance of transient precipitation events; values approaching 1 imply a predominance of long-lived precipitation events. Displayed fractions are calculated from reports within $12.5^{\circ}$. Latitude-longitude windows centered on each $2.5^{\circ}$ grid box.

restricting the analysis to $w w$ values explicitly indicating that lightning was seen or thunder heard $(w w=13$, 17,29 , or 91-99), expressed as a fraction of all nondrizzle precipitation reports. The results, presented in Fig. 21, show an even more dramatic regional variation than was the case for Fig. 20 (note the introduction of a logarithmic scale in the shading scheme).

Clearly, the climatological tendency of precipitation to be accompanied by thunderstorms is highly nonuniform, even throughout the Tropics, with the preferred regions for thunderstorm occurrence apparently tied closely to the major landmasses. Within those preferred regions, $-10 \%-25 \%$ of all nondrizzle precipitation reports indicate thunderstorm activity, whereas the fraction is as low as $\sim 3 \%$ or less over much of the remaining ocean area, including some areas of the socalled "warm pool" of the western tropical Pacific. Interestingly, the SPCZ provides a modest exception to this generalization, with thunderstorm reports composing approximately $8 \%$ of all precipitation-related reports in the December-May seasons, a significantly higher fraction than is found in much of the Pacific ITCZ. This apparent anomaly may perhaps be related to the relatively large number of islands scattered throughout the SPCZ region, notwithstanding the very small total fractional area covered by land.

Present-weather code 13 (lightning observed at a distance from the station; no thunder heard) constitutes almost one-half of the total thunderstorm reports. Furthermore, the conditions under which distant lightning may be observed are likely to vary widely between different climate zones. For example, it has been the author's experience that lightning associated with isolated thunderstorm cells or dusters can frequently be observed $\sim 100 \mathrm{~km}$ away at night in the Tropics and subtropics, while over the middle latitude oceans, the viewing of distant lightning is often hampered by more widespread cloudiness and precipitation.

In view of this additional ambiguity in the interpretation of Fig. 21, the raw COADS data were again reanalyzed, this time excluding $w w=13$ and thus restricting the analysis to reports indicating that a thunderstorm actually occurred (i.e., thunder was heard) at the ship's location at or just prior to the observation time. It was found, however, that this modification does not greatly alter the general spatial patterns of thunderstorm activity described above, though it does reduce the overall frequencies. 
4) Persistence of precipitation

As indicated earlier, some ww values refer to precipitation observed during the preceding hour but not at the actual time of the observation, while others refer to precipitation at the station at the time of the observation. The relative frequencies of the two groups contain information on the temporal scale, or persistence, of individual precipitation events. For example, if all precipitation received at a location is contributed by extremely brief showers, then the likelihood of recording precipitation during the preceding hour can be considerably higher than the likelihood of recording precipitation at the actual time of the observation. If, on the other hand, precipitation events consist of relatively long periods of continuous precipitation, then precipitation occurring during the previous hour is less likely to end before the nominal observation time; hence, the relative frequency of reports of precipitation at the time of the observation increases.

Figure 22 depicts the ratio of the frequency of reports indicating non-drizzle-intensity precipitation at the time of the observation (i.e., the climatological "instantaneous" probability of nondrizzle precipitation) that of all reports of nondrizzle precipitation at the station, including precipitation observed during the preceding hour (i.e., the climatological 1-h probability of precipitation). Throughout most of the high latitudes, the ratio exceeds $0.7-0.8$, consistent with the expectation that high-latitude precipitation is largely stratiform in character and is thus associated with relatively persistent precipitation. In the subtropical high pressure zones, on the other hand, the ratio is often less that 0.5 , confirming the expectation that precipitation there is associated with more transient or localized precipitation events, such as trade wind cumulus showers. Interestingly, ratios are generally somewhat higher in the Northern Hemisphere subtropics than in the Southern Hemisphere subtropics, except during the Northern Hemisphere summer.

Other minor features are apparent whose explanation is less obvious. For example, in all but the DJF season, the maximum ratio $(>0.7)$ for the Tropics and subtropics is consistently found within the short segment of Pacific ITCZ between $120^{\circ}$ and $135^{\circ} \mathrm{W}$, suggesting that, climatologically, this region is somewhat anomalous regarding the occurrence of longer-lived and/or more stratiform precipitation events.

\section{Conclusions}

One of the primary motivations behind the present study was the need to develop an objective, if obviously incomplete, basis for predicting or assessing the general performance of satellite rainfall estimation algorithms over remote areas of the global oceans. Several results of the COADS-derived present-weather statistics are significant in this context:

1) Precipitation frequencies are apparently quite high $(-10 \%-20+\%)$ in the far southern latitudes and increase monotonically toward the Antarctic coast. This observation runs counter to the results yielded by the majority of the satellite microwave algorithms submitted to the First Precipitation [Algorithm] Intercomparison Project (PIP-1) (Barrett et al. 1994a), most of which produced very low $(\sim 1 \%)$ frequencies of precipitation at $50^{\circ} \mathrm{S}$ and/or decreasing frequencies toward Antarctica. The striking disparity between satellite and surface observations suggests that the passive microwave detection of lighter, shallower, and/or frozen precipitation typical of the polar environment (viz. Fig. 19) is an area requiring additional attention. Similar differences were noted between the general patterns of precipitation frequency in Fig. 8 and the MSU-derived rainfall climatology of Spencer (1993). However, in the latter case, the differences could be reconciled if the Spencer method is correctly seeing a significant decrease in mean precipitation intensity (within precipitation) poleward of the storm track axes.

2) The subtropical high pressure zones west of South America and Africa are comparatively dry but are not completely devoid of precipitation. Indeed, climatological frequencies of nondrizzle precipitation as high as $1 \%-4 \%$ are found in some regions where most PIP-1 submissions failed to detect any precipitation at all over a 4-month period (AugustNovember 1987). Infrared-based algorithms (e.g., Arkin and Janowiak 1993) also consistently yield extremely low (much less than $0.5 \mathrm{~mm}$ day $^{-1}$ ) rainfall amounts throughout rather large regions of the subtropical oceans. For these estimates to be compatible with the frequencies derived here, average rainfall intensities within rain events would have to fall well below $\sim 0.6 \mathrm{~mm} \mathrm{~h}^{-1}$. (A preliminary analysis by the author of ship reports for only the 4-month PIP-1 period appears to rule out the alternative explanation that this period simply coincided with much drier than average conditions in the regions in question.)

Based on the ratio of 1-h frequencies to instantaneous frequencies (Fig. 22), it seems likely that precipitation of greater intensity does occur with some regularity in much of the subtropical dry zone, but that it takes the form of scattered, transient showers, which are too small to be detected with the 12-25-km resolution of the SSM/I and which have tops too warm to be detected by IR 
threshold techniques. Since there is no obvious way to overcome either difficulty using currently operational sensors, it could prove impossible for any satellite technique to give reliable rainfall estimates within these regions until such time as active microwave sensors and/or higher-resolution passive microwave sensors become available in the latter part of this decade.

3) In general, the results presented in Figs. 17-22 suggest that the spatial scale and microphysical character of precipitation varies strongly with location and season, even within a given latitude belt. Since satellite rainfall algorithms are known to be sensitive to some of these properties, it seems unlikely that any satellite technique can be made to yield unbiased results globally without the benefit of careful region-by-region calibration. In this context, it should perhaps be of concern that many of the low-latitude radar sites most widely used for overwater calibration of satellite algorithms (e.g., U.S. Gulf and Atlantic coastal sites; Darwin, Australia) appear to be located in regions of anomalously high thunderstorm activity relative to the overall occurrence of precipitation.

On the other hand, ship-derived precipitation statistics of the type presented in this paper may be of some value for segmenting the global oceans into zones of relatively homogeneous precipitation properties. Within such zones, a satellite retrieval technique might perhaps be expected to respond in a more consistent manner to precipitation.

From a purely climatological perspective, the following additional features are particularly noteworthy:

1) The frequency of thunderstorm reports, relative to all precipitation reports (Fig. 21), is strongly region dependent, even within the Tropics. In general, thunderstorm activity is favored within $1000-3000 \mathrm{~km}$ of landmasses, while being quite rare at greater distances, even within the ITCZ. Satellite-based studies of midnight lightning occurrence (Orville and Henderson 1986; Goodman and Christian 1993) had already revealed a very strong land-ocean contrast in the occurrence of lightning, and Zipser (1994) has specifically focused on the apparent rarity of lightning over the ocean, using shipboard observations taken from the Global Atmospheric Research Program Atlantic Tropical Experiment (GATE). All of these studies, however, primarily highlight the sharp gradient in lightning activity that is found in the immediate vicinity of the coastline. The present analyses extend the picture not only by quantifying the relative reporting of oceanic lightning activity on a global basis, but also by highlighting the apparently vital influence of land on thunderstorm activity out to considerable distances over the open ocean. It is also interesting to note that even the observations of reduced updraft speeds and modified cloud microphysical properties that Zipser (1994) cited as characterizing overocean convective precipitation were nonetheless taken in regions (e.g., near Taiwan, near Darwin, and in the GATE region off the coast of Africa) of comparatively high thunderstorm activity, leading one to wonder what aircraft observations of ITCZ convection near $130^{\circ} \mathrm{W}$ during September-November might reveal about cloud properties there.

2) Both the latitudinal frequency of precipitation of all intensities (Figs. 11-13) and the fraction of precipitation that falls as snow (Fig. 19) show very little seasonal variation in the Southern Hemisphere. The frequency of apparent convective activity (Fig. 14), however, shows considerable seasonal variability, with sharp winter maxima occurring near $38^{\circ}$ latitude in both hemispheres.

3) Drizzle is the preferred form of precipitation in a number of well-defined regions (Fig. 17), most of which coincide with known regions of persistent marine stratus and stratocumulus. Less well documented, however, is a rather narrow but pronounced tongue of high drizzle occurrence (relative to other forms of precipitation) extending westward from South America just south of the equator during the June-November months. As noted in section $4 \mathrm{e}(1)$, this feature appears be associated with moist southerly flow over the cooler sea surface temperatures on the south side of the equatorial front with the seasonality of the drizzle feature coinciding both with the period of maximum intensity of the equatorial front (Deser et al. 1993) and with the so-called garúa or cool/dry season that affects the nearby Galapagos Islands (Jackson 1993).

Since it is believed that some of the climatological characteristics of oceanic precipitation described in this paper have not been fully documented or explained in the past, it is hoped that these results will stimulate new discussion and research regarding the relationship between climate-scale dynamics and the occurrence and character of surface precipitation over the ocean. Future work may include an examination of the relationship between COADS-derived oceanic precipitation patterns and the phase of the EI Niño/Southern Oscillation. The $2.5^{\circ}$ gridded present-weather histogram produced as part of this study has been archived as a computer-readable data file and is available from the author or from the Scientific Computing Division, National Center for Atmospheric Research. 
Acknowledgments. The author acknowledges helpful discussions with Carole Hahn (CIRES, Boulder, Colorado) and Stephen G. Warren (Atmospheric Sciences Department, University of Washington) regarding the analysis of ship present-weather reports. Michael Laing (Weather Bureau, South Africa) and Patrick Haines (Purdue University) were instrumental in obtaining a copy of the weather log from the S.A. Agulhas. Steve Worley (Scientific Computing Division, National Center for Atmospheric Research) is gratefully acknowledged for his assistance in obtaining the COADS dataset. Robert Quayle, Alan McNab, Joseph Elms, and Stephen Klein contributed valuable comments and information, as did two anonymous reviewers. This study was supported in part by NASA Grants NAGW-2984 and NAGW-3944.

\section{References}

Arkin, P. A., and J. E. Janowiak, 1993: Tropical and subtropical precipitation. Atlas of Satellite Observations Related to Global Change, R.J. Gurney, J.L. Foster, and C.L. Parkinsons, Eds., Cambridge University Press, 165-180.

- , and P. Xie, 1994: The Global Precipitation Climatology Project: First Algorithm Intercomparison Project. Bull. Amer. Meteor. Soc., 75, 401-419.

Barrett, E. C., J. Dodge, M. Goodman, J. Janowiak, and E. Smith, 1994a: The First WetNet Intercomparison Project (PIP-I), Remote Sens. Rev., 11, 49-60.

- and Coauthors, 1994b: The first Wet-Net Precipitation Intercomparison Project: Interpretation of results. Remote Sens. Rev., 11, 303-373.

Deser, C., J. J. Bates, and S. Wahl, 1993: The influence of sea surface temperature gradients on stratiform cloudiness along the equatorial front in the Pacific Ocean. J. Climate, 6, 1172-1180.

Dorman, C. E., and R. H. Bourke, 1979: Precipitation over the Pacific Ocean, $30^{\circ} \mathrm{S}$ to $60^{\circ} \mathrm{N}$. Mon. Wea. Rev., 107, 896-910.

- , and -1981 : Precipitation over the Atlantic Ocean, $30^{\circ} \mathrm{S}$ to $70^{\circ}$ N. Mon. Wea. Rev., 109, 554-563.

FMH, 1978: Federal Meteorological Handbook No. 1, Surface Observations (serial). $354 \mathrm{pp}$. [Available from the Superintendent of Documents, U.S. Government Printing Office, Washington, D.C. 20402.]

Goodman, S. J, and H. J. Christian, 1993: Global observations of lightning. Atlas of Satellite Observations Related to Global Change, R. J. Gurney, J. L. Foster, and C. L. Parkinsons, Eds., Cambridge University Press, 191-222.

Hahn, C. J., S. G. Warren, and J. London, 1994:Climatological Data for Clouds over the Globe from Surface Observations, 19821991: The Total Cloud Edition. Numerical Data Package NDP026A, 42 pp. [Available from Carbon Dioxide Information Analysis Center, Ridge National Laboratory, P.O. Box 2008, Oak Ridge, TN 27831-6050.]

- _ - and - 1995: The effect of moonlight on observation of cloud cover at night, and application to cloud climatology. $J$. Climate, 8, 1429-1446.

Huschke, R. E., 1959: Glossary of Meteorology. Amer. Meteor. Soc., $638 \mathrm{pp}$.

Jackson, M. H., 1993: Galapágos: A Natural History. University of Calgary Press, $316 \mathrm{pp}$.
Jaeger, L., 1983: Monthly and areal patterns of mean global precipitation. Variations in the Global Water Budget, A. Street-Perrott, M. Beran, and R. Ratcliffe, Eds., D. Reidel, 129-140.

Legates, D. R., and C. J. Willmott, 1990: Mean seasonal and spatial variability in gauge corrected, global precipitation. Int. J. Climatol., 10, 111-127.

Orville, R. E., and R. W. Henderson, 1986: Global distribution of midnight lightning: September 1977 to August 1978. Mon. Wea. Rev., 114, 2640-2653.

Quayle, R. G., 1974: A climatic comparison of ocean weather station and transient ship records, NOAA, Environmental Data Service. Mar. Wea. Log, 18, 307-311.

Reed, R. K., 1979: On the relationship between the amount and frequency of precipitation over the ocean. J. Appl. Meteor., 18, $692-696$.

- and W. P. Elliott 1979: New precipitation maps for the North Atlantic and North Pacific Oceans. J. Geophys. Res., 84, 78397846.

Simpson, J., R. F. Adler, and G. R. North, 1988: A proposed Tropical Rainfall Measuring Mission (TRMM) satellite. Bull. Amer. Meteor. Soc., 69, 278-295.

Slutz, R. J., S. J. Lubker, J. D. Hiscox, S. D. Woodruff, R. L. Jenne, D. H. Joseph, P. M. Steurer, and J. D. Elms, 1985: Comprehensive Ocean-Atmosphere Data Set: Release 1. NOAA Environmental Research Laboratories, Climate Research Program, 286 pp. [NTIS PB-105723.]

Spencer, R. W., 1993: Global oceanic precipitation from the MSU during 1979-91 and comparisons to other climatologies. $J$. Climate, 6, 1301-1326.

Tucker, G. B., 1961: Precipitation over the North Atlantic Ocean. Quart. J. Roy. Meteor. Soc., 87, 147-158.

U.S. Navy, 1974:U.S. Navy Marine Climatic Atlas of the World. Vol. 1. North Atlantic Ocean. NAVAIR 50-1C-528, Naval Weather Service Command, Asheville, NC, $371 \mathrm{pp}$.

_ 1976: U. S. Navy Marine Climatic Atlas of the World. Vol. 2 , North Pacific Ocean. NAVAIR 50-1C-529, Naval Oceanography and Meteorology, Asheville, NC, $388 \mathrm{pp}$.

- 1977: U. S. Navy Marine Climatic Atlas of the World. Vol. 3 , Indian Ocean. NAVAIR 50-1C-530, Naval Weather Service Command, Asheville, NC, $348 \mathrm{pp}$.

- 1978: U. S. Navy Marine Climatic Atlas of the World. Vol. 4, South Atlantic Ocean. NAVAIR 50-1C-531, Naval Oceanography and Meteorology, Asheville, NC, 325 pp.

_, 1979: U. S. Navy Marine Climatic Atlas of the World. Vol. 5 , South Pacific Ocean, NAVAIR 50-1C-532, Naval Oceanography Command, Asheville, NC, $350 \mathrm{pp}$.

Warren, S. G., C. J. Hahn, J. London, R. M. Chervin, and R. L. Jenne 1988: Global distribution of total cloud cover and cloud type amounts over the ocean. NCAR Tech. Note NCARTN-317+STR, Boulder, CO, $29 \mathrm{pp}+200$ maps.

Wilheit, T. T., 1986: Some comments on passive microwave measurement of rain. Bull. Amer. Meteor. Soc., 67, 1226-1232.

Woodruff, S. D., R. J. Slutz, R. L. Jenne, and P. M. Steuer, 1987: A comprehensive ocean-atmospheric data set. Bull. Amer. Meteor. Soc., 68, 1239-1250.

World Meteorological Organization, 1974: Manualon Codes, Vol. 1. WMO Publ. 306, WMO

Zipser, E. J., 1994: Deep cumulonimbus cloud systems in the Tropics with and without lightning. Mon. Wea. Rev., 122, 1837-1851.

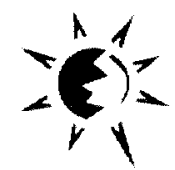

